\title{
Acinetobacter Baumannii: Researchers' Scientific Cooperation Network in Three Decades
}

\author{
Farshid Danesh*1 (D), Somayeh GhaviDel ${ }^{2}$ (D) Maryam Emami $^{3}$ iD
}

1. Information Management Research Department, Regional Information Center for Science and Technology (RICeST), Shiraz, Iran

2. Department of Knowledge and Information Science, School of Psychology and Educational Sciences, Kharazmi University, Tehran, Iran

\section{ABSTRACT}

Background: Acinetobacter baumannii is one of the most common challenging pathogens in causing serious infections in intensive care units of modern hospital systems around the world and poses a serious threat to public and patient health. This study aims to analyze the network of scientific and empirical collaborations of $A$. baumannii researchers in the last three decades.

Materials \& Methods: The present study was performed using the Co-citation analysis technique. All A. baumannii publications indexed in the Web of Science Core Collection for the period 1990-2019 are the statistical population of the study. After an advanced search, 4473 documents were retrieved. A total of 18343 authors contributed to the publication of the retrieved documents. Ravar PreMap 1.0.0.0, NetDraw, and UCINET 6.528.0.0 software were utilized for data analysis.

Results: Data analysis showed that the global publication of $A$. baumannii has risen. "Clinical Infectious Diseases," was the best journal, and "Seifert, Harald," the most influential researcher, and "Seifert, Harald * Higgins, Paul G," were identified as the best co-citation pair. Top researchers in A. baumannii were "Beceiro," "Alejandro," "HSU Li Yang," and "Seifert, Harald," respectively, based on degree, betweenness and closeness centrality indicators.

Conclusion: Analysis of social networks $A$. baumannii presents an objective and realistic view to experts and planners in Medical Sciences. Also, the structure of $A$. baumannii's internal relationships and researchers' connections is determined objectively. Finally, researchers get acquainted with journals, scientists and organizations that are proliferated and effective and plan to collaborate with them in the future

Keywords: Acinetobacter Baumannii; Co-citation analysis, Social network analysis; Scientometrics; Bibliometrics

Received: 2020/03/14; Accepted: 2020/05/28; Published Online: 2020/06/18

\begin{tabular}{|c|c|}
\hline Corresponding Information: & $\begin{array}{l}\text { Farshid Danesh, Information Management Research Department, Regional Information Center for Science and Technology } \\
\text { (RICeST), Shiraz, Iran Email: farshiddanesh@ @icest.ac.ir }\end{array}$ \\
\hline (c) ( & $\begin{array}{l}\text { is an original open-access article distributed under the terms of the Creative } \\
\text { ribution of the material just in noncommercial usages with proper citation. }\end{array}$ \\
\hline
\end{tabular}

Use your device to scan and read the article online

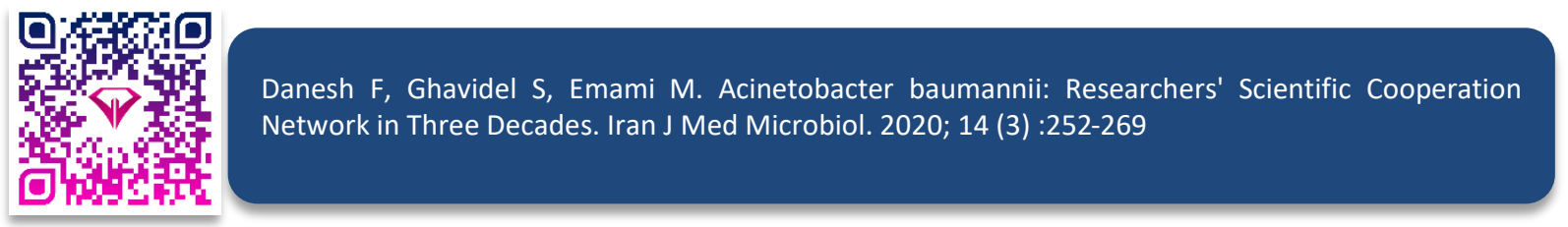

Download citation: BibTeX | RIS | EndNote | Medlars | ProCite | Reference Manager | RefWorks

Send citation to: $\otimes \underline{\text { Mendeley }} \bar{Z}$ Zotero $\mathbb{H}_{\text {RefWorks }}$

\section{Introduction}

Acinetobacter baumannii is one of the most common and effective pathogens in causing serious ICU infections in modern hospital systems around the world (1-5). This hospital pathogen has caused a wide range of infections, including Septicemia and Pneumonia, and has become a significant challenge in health care services, especially hospitals $(3,6-8)$. A. baumannii researchers and specialists have always conducted extensive research in 
various fields due to the challenges, crises, and global impact of this pathogen.

Co-citation analysis is one of the scientometric techniques that is used as a method in analyzing the intellectual structure of scientists and their publications and identifying principal authors and publications in different areas of research $(15,14)$. Due to the importance of the scientometrics study of $A$. baumannii's international publications, the main issue of this article is to visualize the scientific collaboration network and the citations of $A$. baumannii's researchers using the methods of co-citation analysis and social network analysis from 1990 to 2019. Conducting such research and its practical results will be of great help to researchers and planners of the healthcare system in the field of strategic and heuristic planning, as well as the implementation of programs at the level of medical sciences organizations and countries (20).

Therefore, it seems necessary to conduct practical, comprehensive, and analytical research in this regard. Visualizing the researchers of $A$. Baumannii's scientific collaboration network is the primary goal of this study.

\section{Materials and Methods}

The method used in this paper is co-citation analysis. The statistical population is all $A$. Baumannii indexed publications from 1990 to 2019 in the Web of Science Core Collection (WOSCC). A total of 4473 records were retrieved after an advanced search for "A. Baumannii" with the "TI" tag using Ravar PreMap, UCINET 6.528.0.0, and Netdraw 1.0.0.0 for preprocessing and analyzing the data (18)

\section{Results}

\section{The Growth Trend of Acinetobacter baumannii Publications}

A. baumannii's number of Publications rose from 2 in 1990 to 475 in 2019. The data in Figure 1 showed that $A$. baumannii's publication trend has been growing in the last three decades.

\section{Ranking of Acinetobacter baumannii's Top Journals Based on IF}

The data in Table 1 showed that the best journal is "Clinical Infectious Diseases," with an impact factor of 9.05 .

\section{The Most Effective Acinetobacter baumannii Researchers}

With 4365 citations, "Seifert, Harald" from Germany and affiliated with University Hospital of Cologne, ranked first among the most effective researchers in the $A$. Baumannii research domain (Table 2).

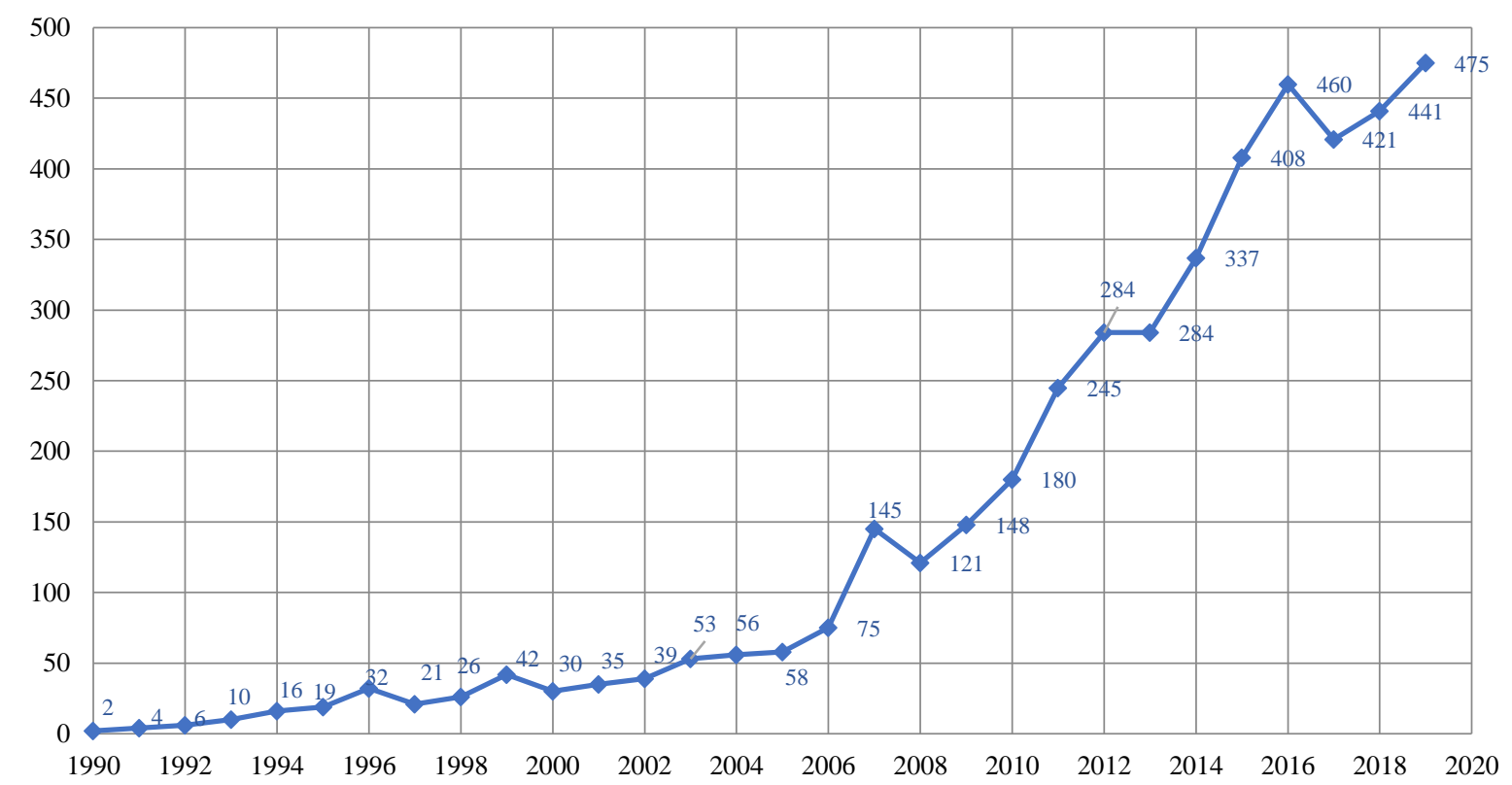

Figure 1. The growth trend of Acinetobacter baumannii's publication in WOSCC (1990 to 2019) 
Table 1. Top Acinetobacter baumannii's journals in WOSCC (1990-2019) Based on Impact Factor

\begin{tabular}{|c|c|c|c|c|c|c|c|c|c|}
\hline Rank & Journal & 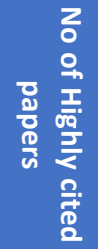 & 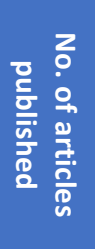 & $\begin{array}{l}\stackrel{8}{8} \\
\text { 龸 }\end{array}$ & Publisher & 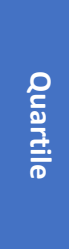 & 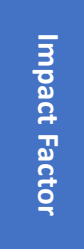 & 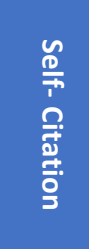 & 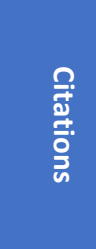 \\
\hline 1 & Clinical Infectious Diseases & 1 & 42 & \multirow{3}{*}{ UK } & Oxford University & Q1 & 9.05 & 47 & 4587 \\
\hline 2 & $\begin{array}{l}\text { Clinical Microbiology and } \\
\text { Infection }\end{array}$ & 0 & 79 & & Elsevier & Q1 & 6.42 & 119 & 4162 \\
\hline 3 & $\begin{array}{l}\text { Journal of Antimicrobial } \\
\text { Chemotherapy }\end{array}$ & 6 & 160 & & Oxford University & Q1 & 5.11 & 272 & 8068 \\
\hline 4 & $\begin{array}{l}\text { Journal of Clinical } \\
\text { Microbiology }\end{array}$ & 0 & 111 & \multirow{2}{*}{ USA } & $\begin{array}{l}\text { American Society for } \\
\text { Microbiology }\end{array}$ & Q1 & 4.95 & 267 & 7173 \\
\hline 5 & $\begin{array}{l}\text { Antimicrobial Agents and } \\
\text { Chemotherapy }\end{array}$ & 6 & 337 & & $\begin{array}{c}\text { American Society for } \\
\text { Microbiology }\end{array}$ & Q1 & 4.71 & 1106 & 16227 \\
\hline
\end{tabular}

Table 2. Effective researchers of Acinetobacter baumannii in WOSCC (1990 - 2019)

\begin{tabular}{|c|ccccccc|c|}
\hline Rank & Author & Country & Affiliation & $\begin{array}{c}\text { Highly cited } \\
\text { papers }\end{array}$ & $\begin{array}{c}\text { Self- } \\
\text { Citation }\end{array}$ & H-index & Record & Citation \\
\hline 1 & Seifert, Harald & Germany & $\begin{array}{c}\text { University Hospital } \\
\text { Cologne }\end{array}$ & 2 & 168 & 24 & 50 & 4365 \\
\hline 2 & $\begin{array}{c}\text { Bonomo, } \\
\text { Robert A }\end{array}$ & USA & $\begin{array}{c}\text { Case Western Reserve } \\
\text { University }\end{array}$ & 2 & 150 & 27 & 71 & 3021 \\
\hline 3 & $\begin{array}{c}\text { Paterson, } \\
\text { David L }\end{array}$ & Australia & $\begin{array}{c}\text { University of } \\
\text { Queensland }\end{array}$ & 1 & 23 & 12 & 15 & 2791 \\
\hline 4 & $\begin{array}{c}\text { Peleg, Anton Y } \\
\text { Nustralia }\end{array}$ & Monash University & 0 & 42 & 14 & 20 & 2694 \\
\hline 5 & $\begin{array}{c}\text { Nordmann, } \\
\text { patrice }\end{array}$ & Switzerland & University of Fribourg & 1 & 93 & 26 & 37 & 2449 \\
\hline
\end{tabular}

\section{Top co-citation pairs in Acinetobacter baumannii}

"Seifert, Harald * Higgins, Paul G" are the authors who have had the most co-citation pairs in $A$. baumannii and ranked first place. The researchers are from Germany and have had 54 co-citation pairs in the last three decades.
Top Acinetobacter baumannii Researchers Based on Degree, Betweenness and Closeness centrality

"Beceiro, Alejandro" with 52-degree centrality, "HSU Li Yang" with 368/1734 betweenness centrality, and "Seifert, Harald" with 0.280 closeness centrality are ranked first in centrality indicators.

Table 3. Top 10 co-citation pairs in Acinetobacter baumannii (1990-2019)

\begin{tabular}{|c|ccc|}
\hline Rank & co-citation pairs & No. of Co-Citations & Countries of co-citation couples \\
\hline 1 & Seifert, Harald * Higgins, Paul G. & 54 & Germany* Germany \\
\hline 2 & Nordmann, patrice * Poirel, Laurent & 52 & Switzerland* Switzerland \\
\hline 3 & Hall, Ruth M. * Kenyon, Johanna J & 29 & Australia* Australia \\
\hline 4 & Chen Te-Li * Kuo-Shu CHEN & 28 & Taiwan* Taiwan \\
\hline 5 & Li Jian * Nation, Roger L. $^{*}$. & 27 & Australia* Australia \\
\hline 6 & Popova, Anastasiya V. * Schneider, Mikhail M. & 27 & USA* USA \\
\hline 7 & Knirel, Yuriy A. * Shashkov Alexander S. & 27 & Russia* Russia \\
\hline 8 & Chen Te-Li * Lee Yi-tzu & 26 & Taiwan* Taiwan \\
\hline 9 & Popova, Anastasiya V. * Knirel, Yuriy A. & 26 & Russia* Russia \\
\hline 10 & Knirel, Yuriy A. * Schneider, Mikhail M. & 26 & Russia* USA \\
\hline
\end{tabular}


Acinetobacter baumannii research network based on centrality indicators

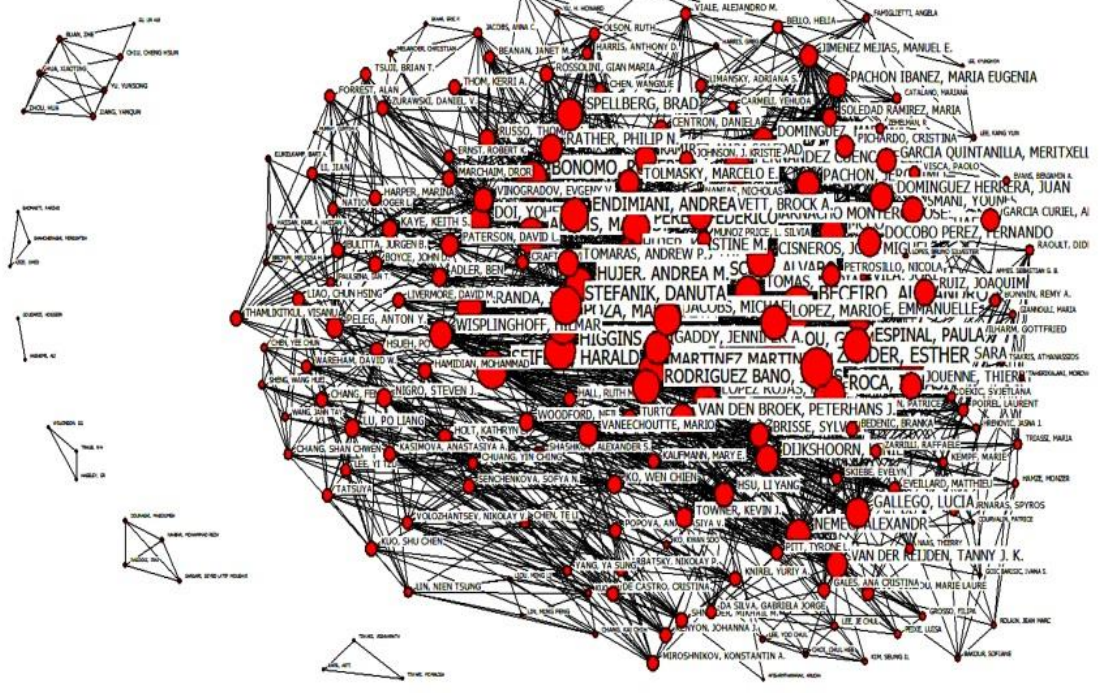

Figure 2. Acinetobacter Baumannii research network based on degree centrality

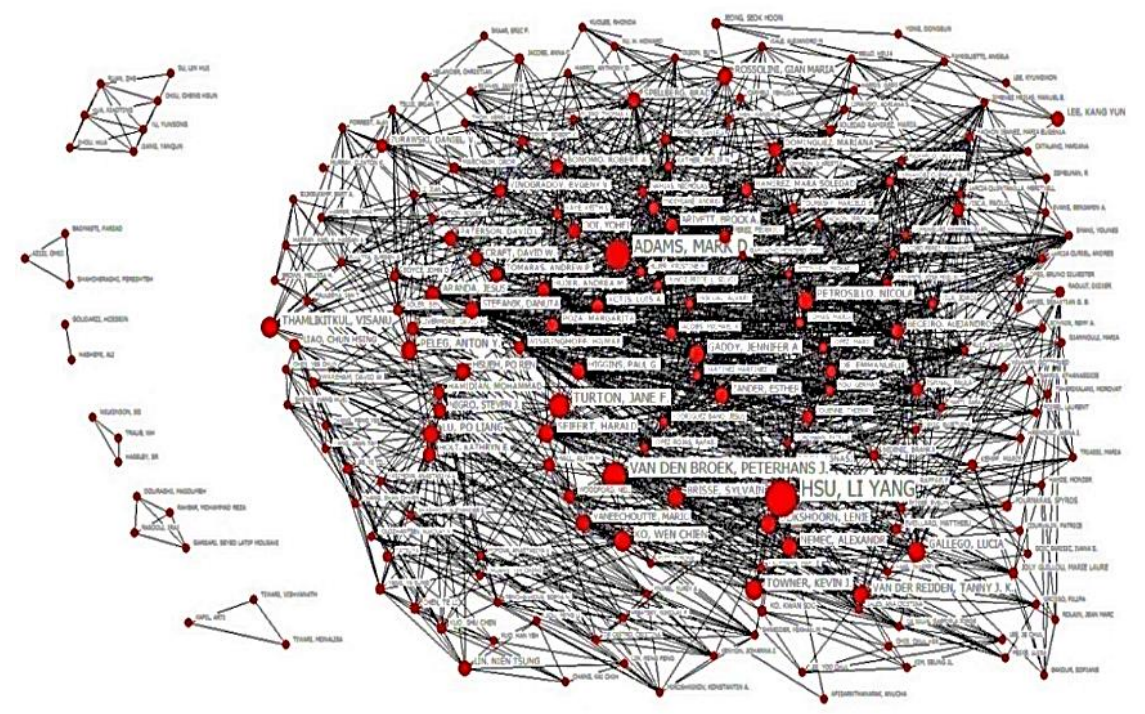

Figure 3. Acinetobacter Baumannii research network based on betweenness centrality

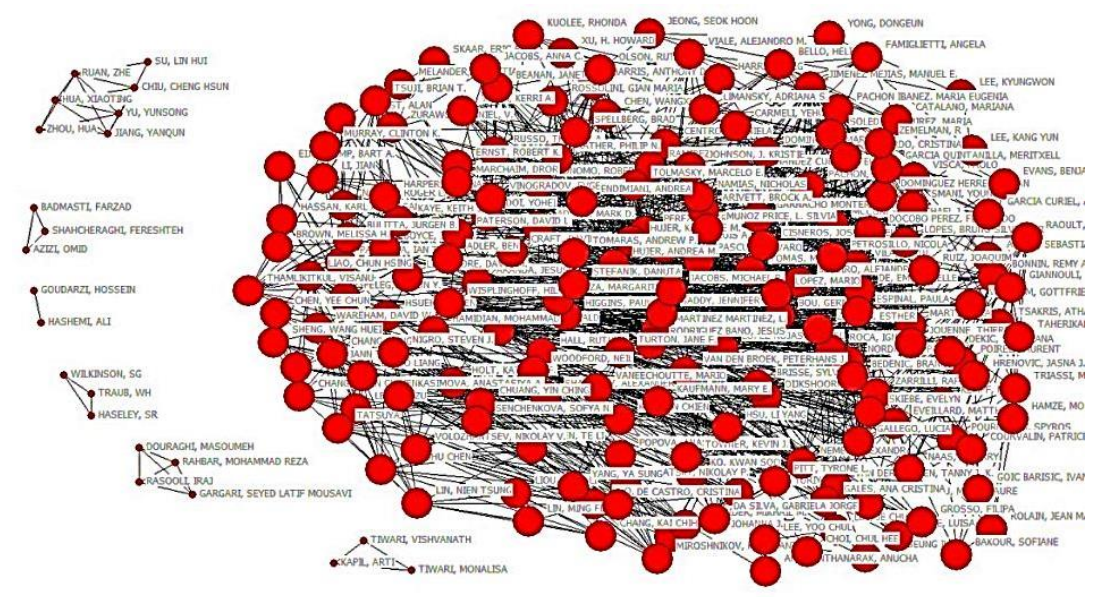

Figure 4. Acinetobacter Baumannii research network based on closeness centrality 


\section{Discussion}

The trend of scientific publications of $A$. Baumannii researchers has been growing in the last three decades. The results of this part of the study are consistent with the results of research by Zeinoun (22), Liao (28), Sweileh (31). "Seifert, Harald" is the most influential researcher, and "Bonomo, Robert A" is the most proliferated one. These results are not consistent with the results of Figg (41) and Huamani (42) but are consistent with the research of Hassanzadeh et al. (30). "Seifert, Harald * Higgins, Paul G," is a co-citation pair who share common research interests.

"Beceiro, Alejandro" has more power in the knowledge flow of network and has a unique role in attracting new researchers to the scientific network (17). "HSU Li Yang," due to its central position in the network, has many relationships with other researchers and has an important strategic position in the overall structure of the collaboration network (17, 40). "Seifert, Harald," with the highest closeness centrality, is closer to other members of the network and has faster access to all researchers on the network than any other so that there can be more citations to his publications $(17,39)$. From this perspective, the results of the present study are consistent with the research of Soheili et al. (37).

\section{Conclusion}

One of the most critical concepts and unique functions of social network analysis is the study of researchers' scientific collaboration network with centrality indicators that determine the importance and effectiveness of researchers and their performance in the cooperation network. Based on this, it is suggested that detailed and independent research of the Iranian $A$. baumannii researchers' collaboration network be conducted.

\section{Acknowledgment}

In this regard, we appreciate the experts for their valuable comments.

\section{Conflict of Interest}

Authors declared no conflict of interests. 


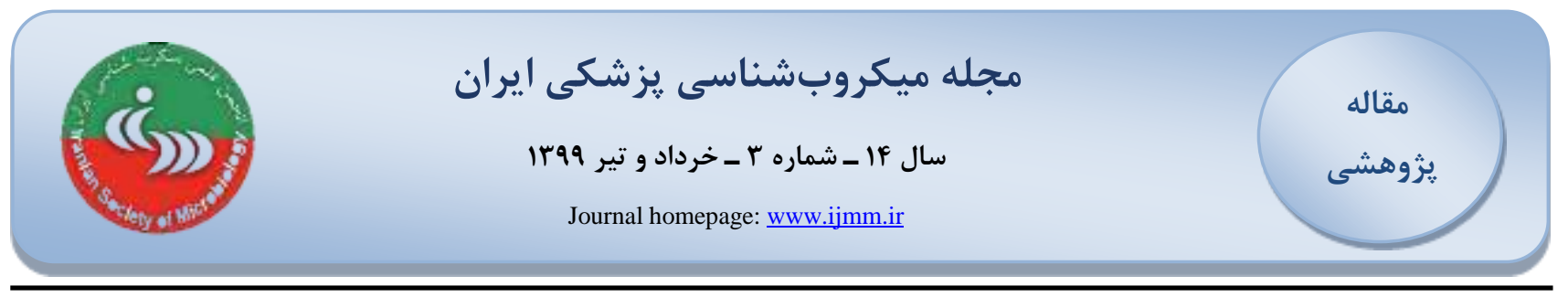

اسينتوياكتر بومانى: شبكه همكارى علمى بُزوهشكران در سه دهه

\author{
فرشيد دانش'"، سميه قويدل '، مريم امامى"
}

I. كروه يروهشى مديريت اطلاعات، مركز منطقهاى اطلاعرسانى علوم و فناروى، شيراز، ايران

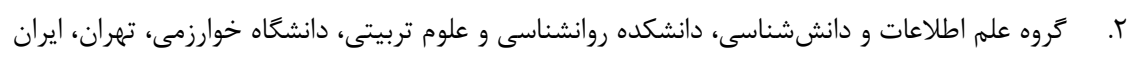

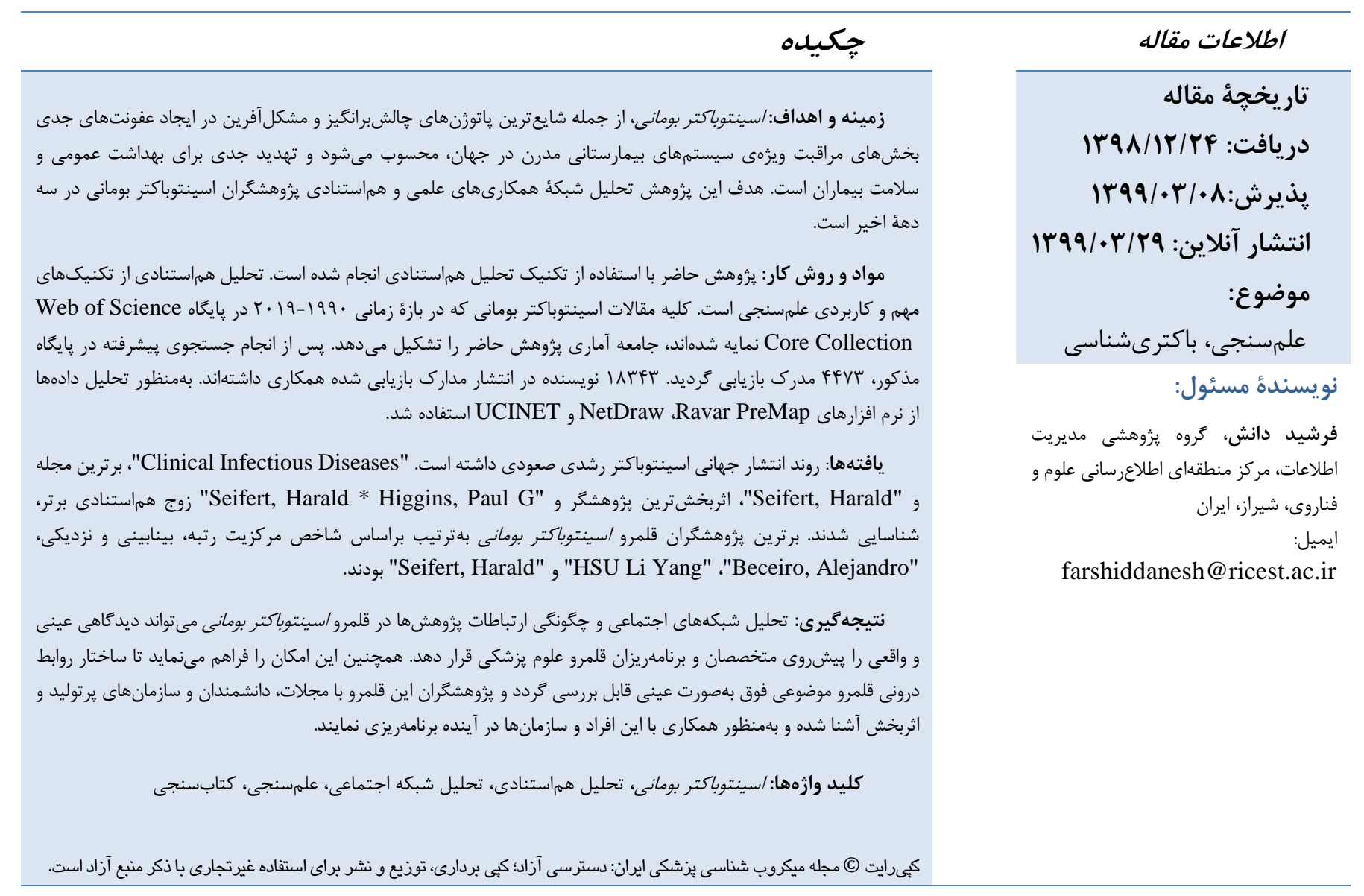

مقلمهه

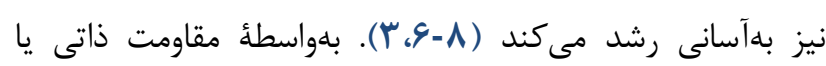

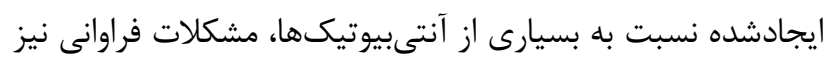

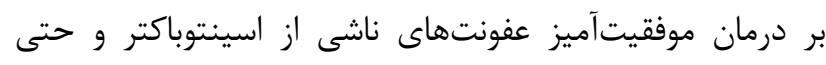

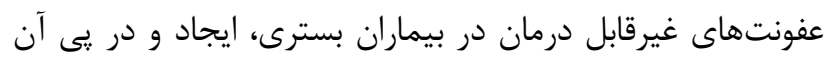

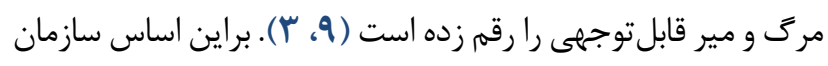

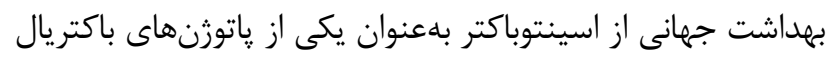

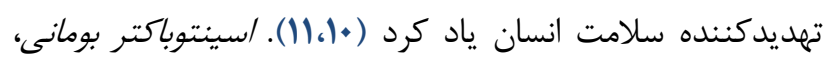

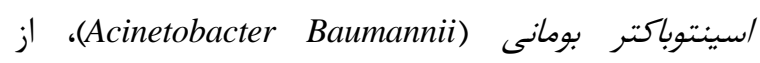

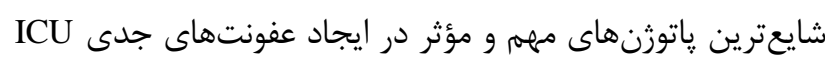

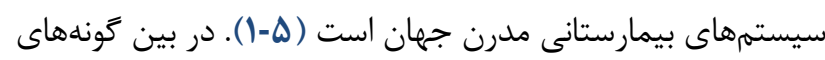

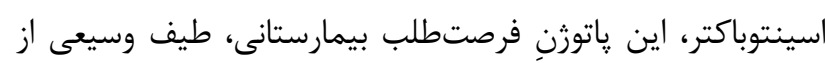
عفونتها نظير سيتىسمى (Septicemia) و پِنومونى (Pneumonia)

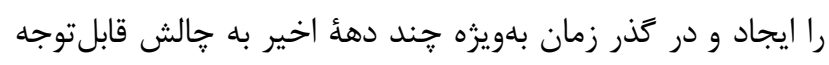

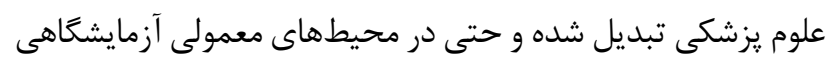


و نيز اجراى برنامهها در سطح كشورها و سازمانهاى علوم يزشكى

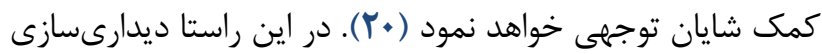

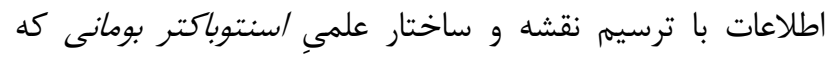

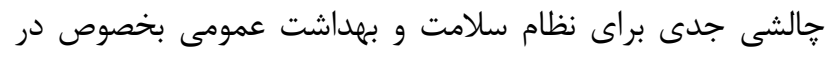

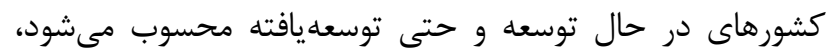

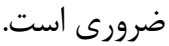

در ادامه اين مقاله، برخى بيشينههاى مرتبط درخصوص

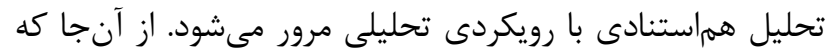

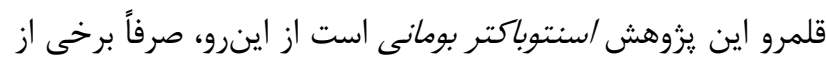

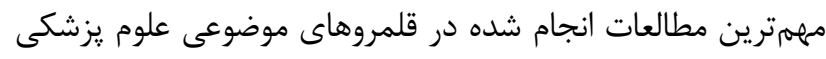

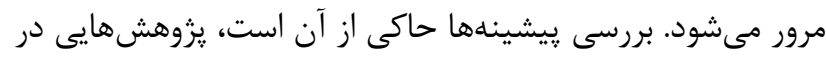

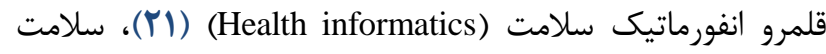
روان (Mental Health) (Yr) (Y)، صدمات دندانى جراحى (Traumatic) (dental injuries

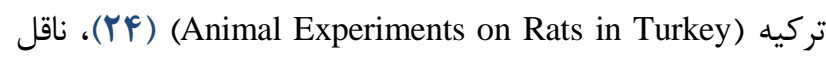

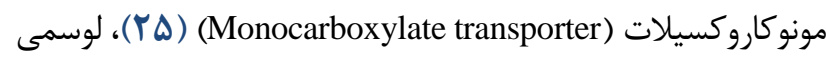

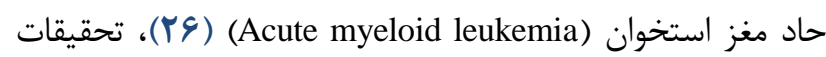
زنتيكي سكته قلبى (Gene research of myocardial infarction)

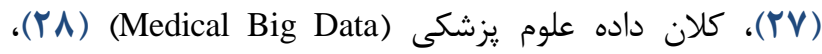

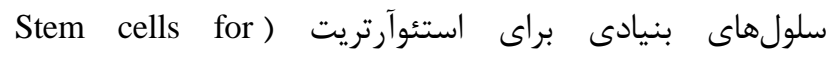

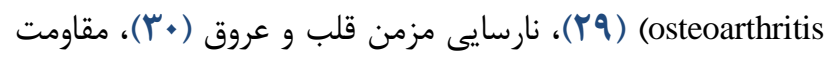

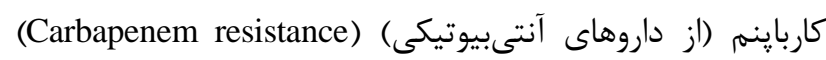
(آآ) با استفاده از روش تحليل هم/استنادى بهشكلى مؤثر در تحليل ساختار فكرى مطالعات علمى و شناسايى شبكه همكارى نويسند

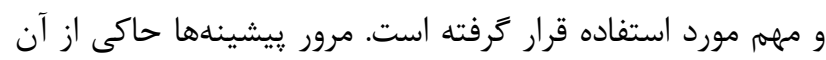

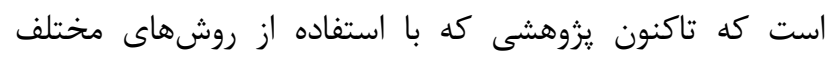

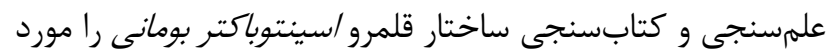

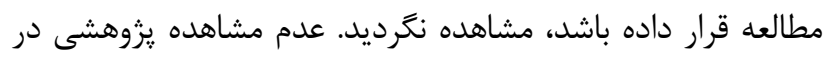

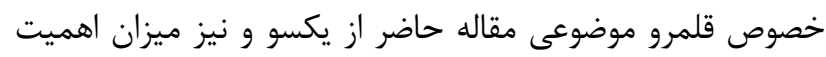
راهبردى موضوع /سينتوباكتر بومانى براى نظام سلامت در سطح

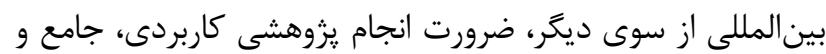
تحليلى در اين خصوص را بيش از ييش آشكار مىنمايد. باتوجه به مطالب مذكور، ديدارىسازى شبكه همكارى علمى

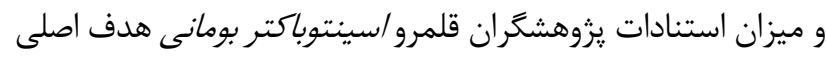

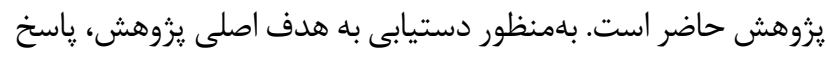
به برخى از يرسشهاى اساسى مانند مطالعه روند رشد انتشارات

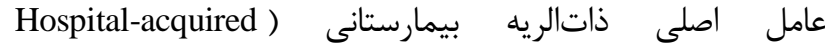
pneumonia

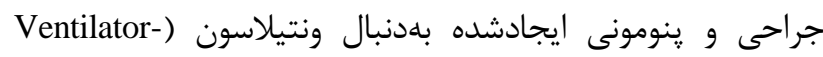
(associated pneumonia

يروهشكَران و متخصصين قلمرو اسينتوباكتر با توجه به

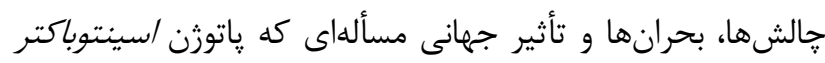

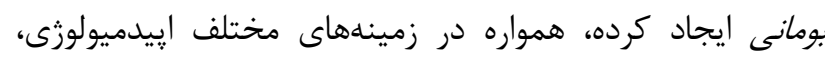

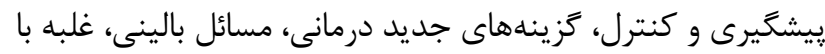

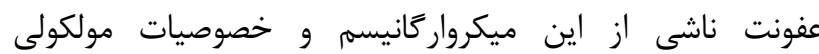

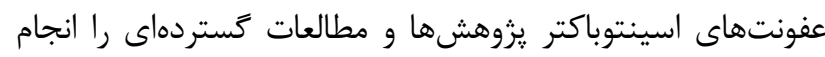

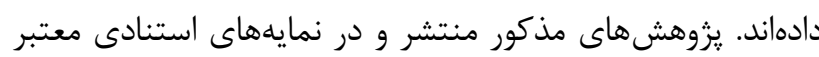

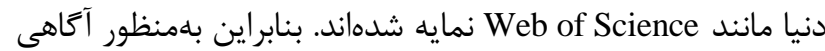

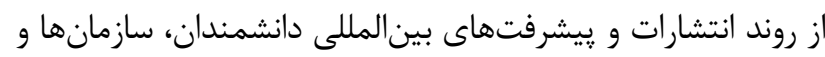

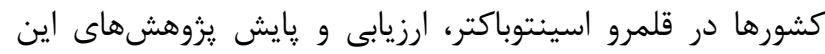

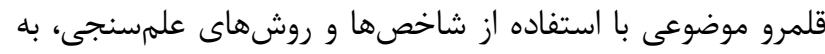

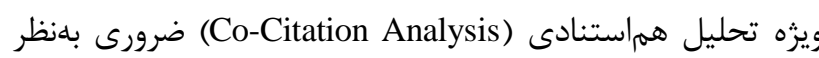
مى رسد.

تحليل هماستنادى، يكى از تكنيكهاى علمسنجى است كه

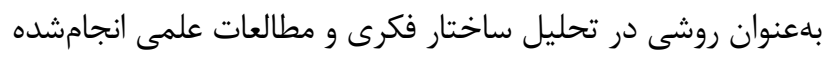

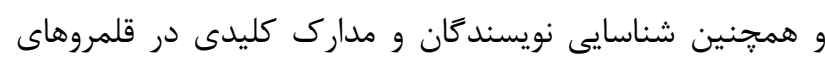

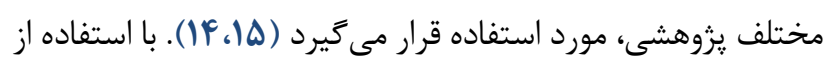
اين روش رشد يزوهشهاى علمى، دنبال كردن يويايى زمينههاى علمى و كشف زمينههاى جديد يزوهشى قابل بررسى است (1)،

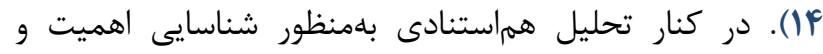

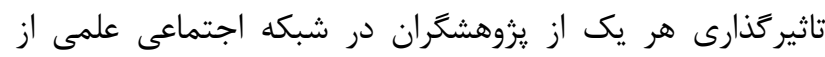

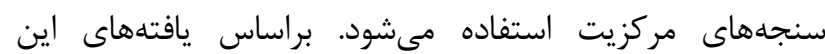
تحليلها، نويسندكانى كه در قلمرو مورد مطالعه، تاثير وسيعترى

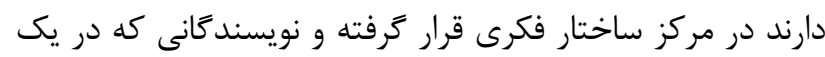

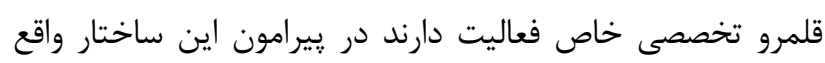

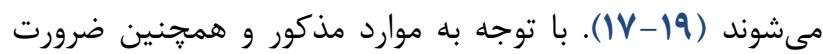
مطالعئ تحليلى انتشارات/سينتوباكتر بومانى در سطح بينالمللى در نظام سلامت، مسأله اصلى اين مقاله ديدارىسازى شبكه همكارى دئل

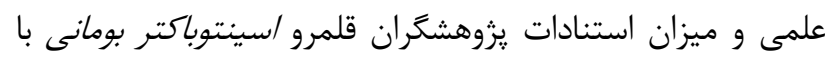
استفاده از روشهاى تحليل هماستنادى و تحليل شبكه اجتماعى

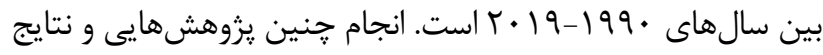

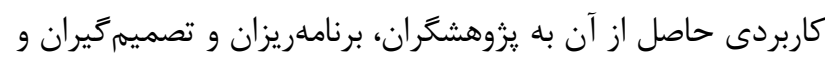
بلهور كلى نظام سلامت در زمينه برنامهريزى بهاى راهبردى و وركان كلان 
براى استخراج زوجهاى هماستنادى تمامى فهرست منابع مقالات

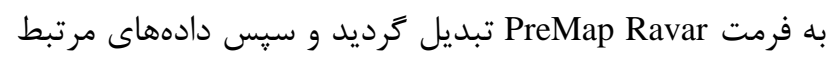

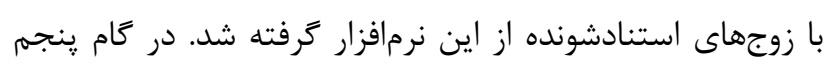

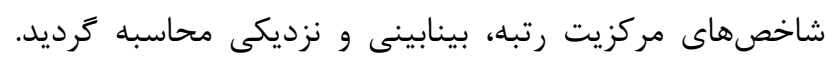

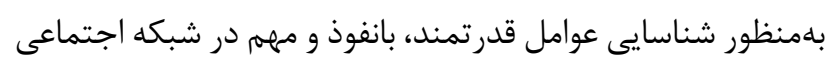

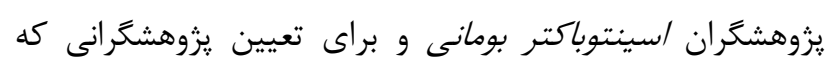

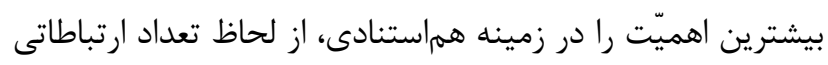

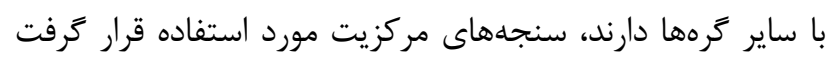

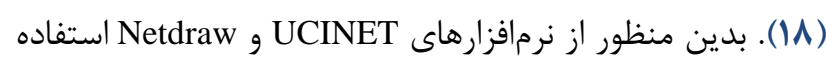
شد. در كام ششم ضريب رشد انتشارات علمى قلمرو /سينتوباكتر

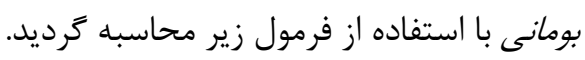

$$
1-2^{R}=\frac{\log _{e} W_{2}-\log _{\varepsilon} W_{1}}{T_{2}-T_{1}}
$$

در اين فرمول مشخص،

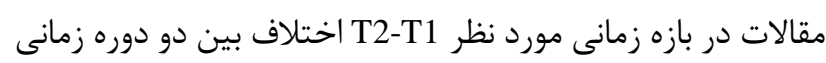

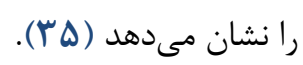

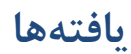

\section{روند رشد انتشارات يخوهشگران قلمرو /سينتوباكتر بومانى}

نكاهى به دادههاى شكل إ حاكى از آن است كه انتشارات

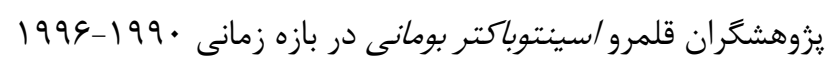

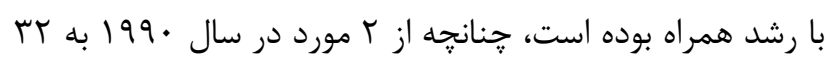

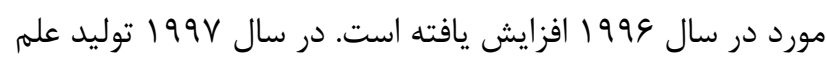

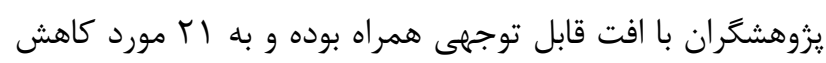

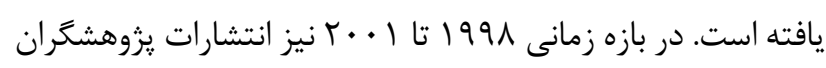

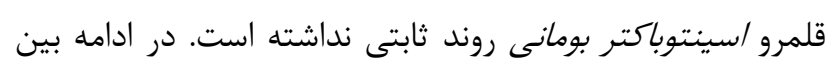

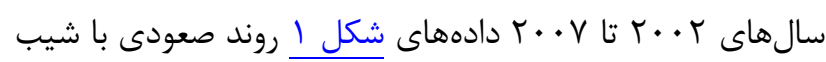

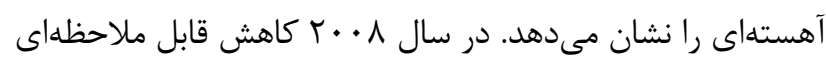

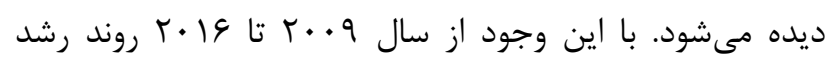

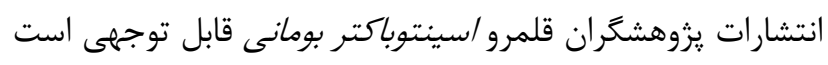

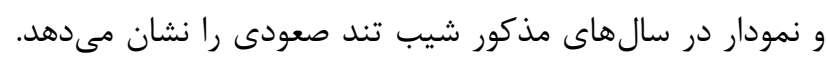

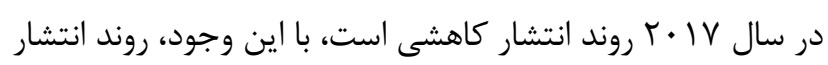

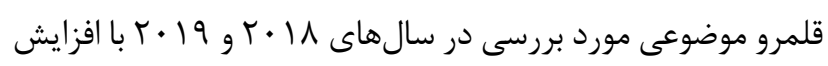

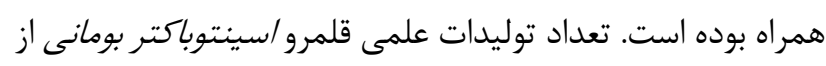

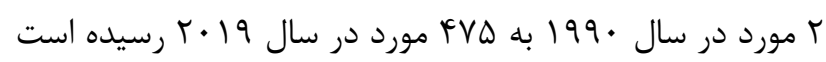

يروهشكران، تعيين توزيع فراوانى انتشارات يزوهشكَران، تعيين

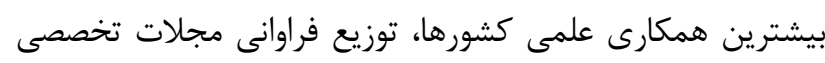

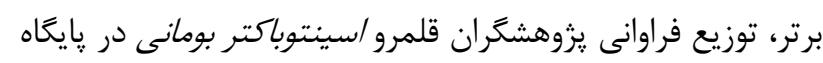
بين سالهاى

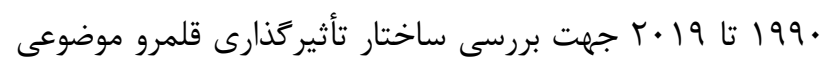
اسينتوباكتر بومانى ضرورى است.

\section{روش يخُوهش}

يزوهش حاضر از نوع مطالعات علمسنجى و با استفاده از تكنيك تحليل هم/اتتنادى با رويكرد تحليلى انجام شده است.

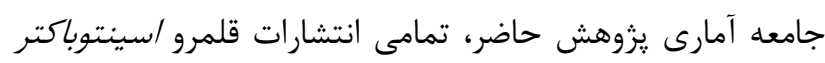

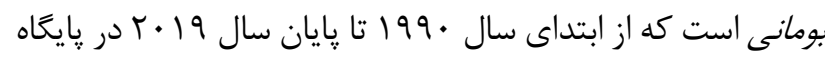

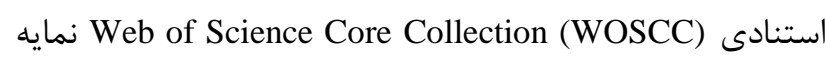

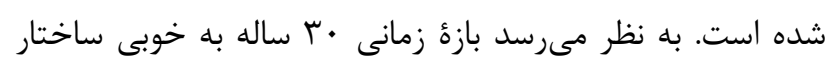

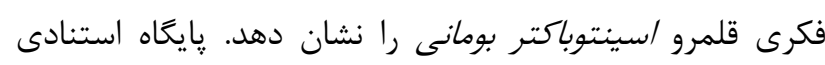
WOSCC

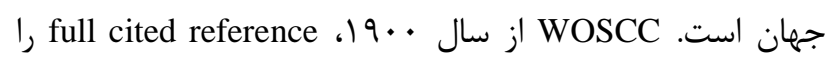

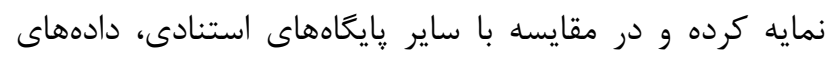

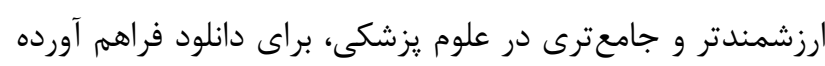

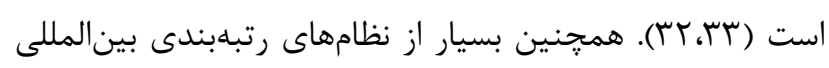

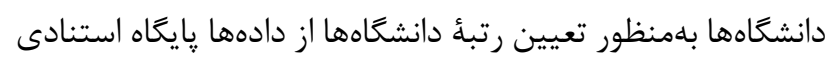
Web of Science

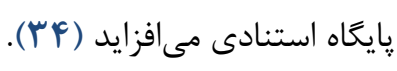

بلمنظور استخراج دادها و اجراى يزوهش در كام نخست،

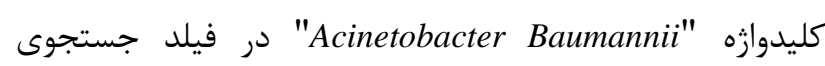

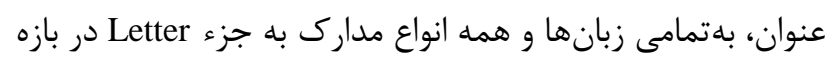

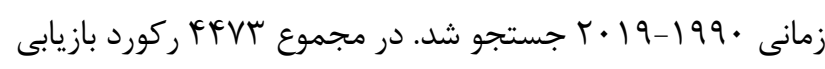

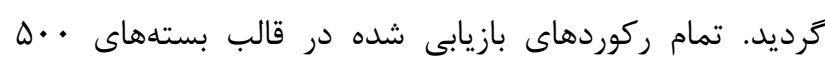

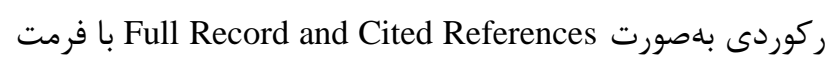
برجّبدار به شكل فايلهاى متنى ساده (Plain Text) دانلود

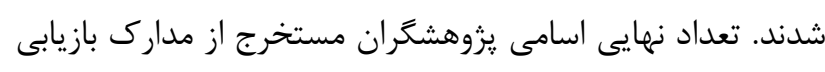

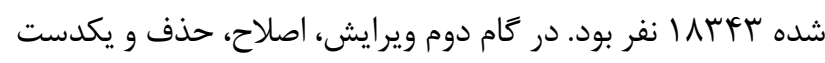

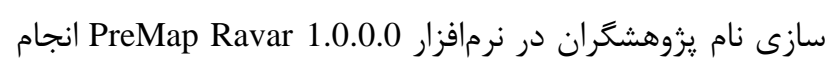

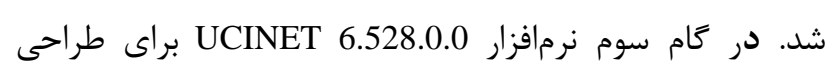

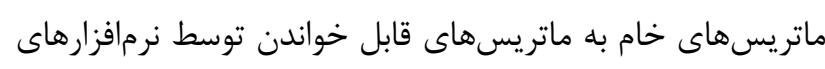

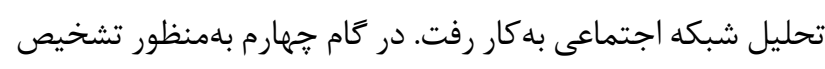

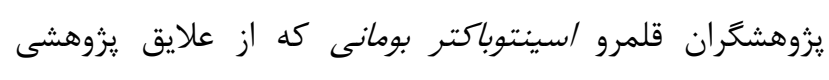
مشتركى برخوردار هستند، زوجهاى هماستنادى استخراج گرديد. 


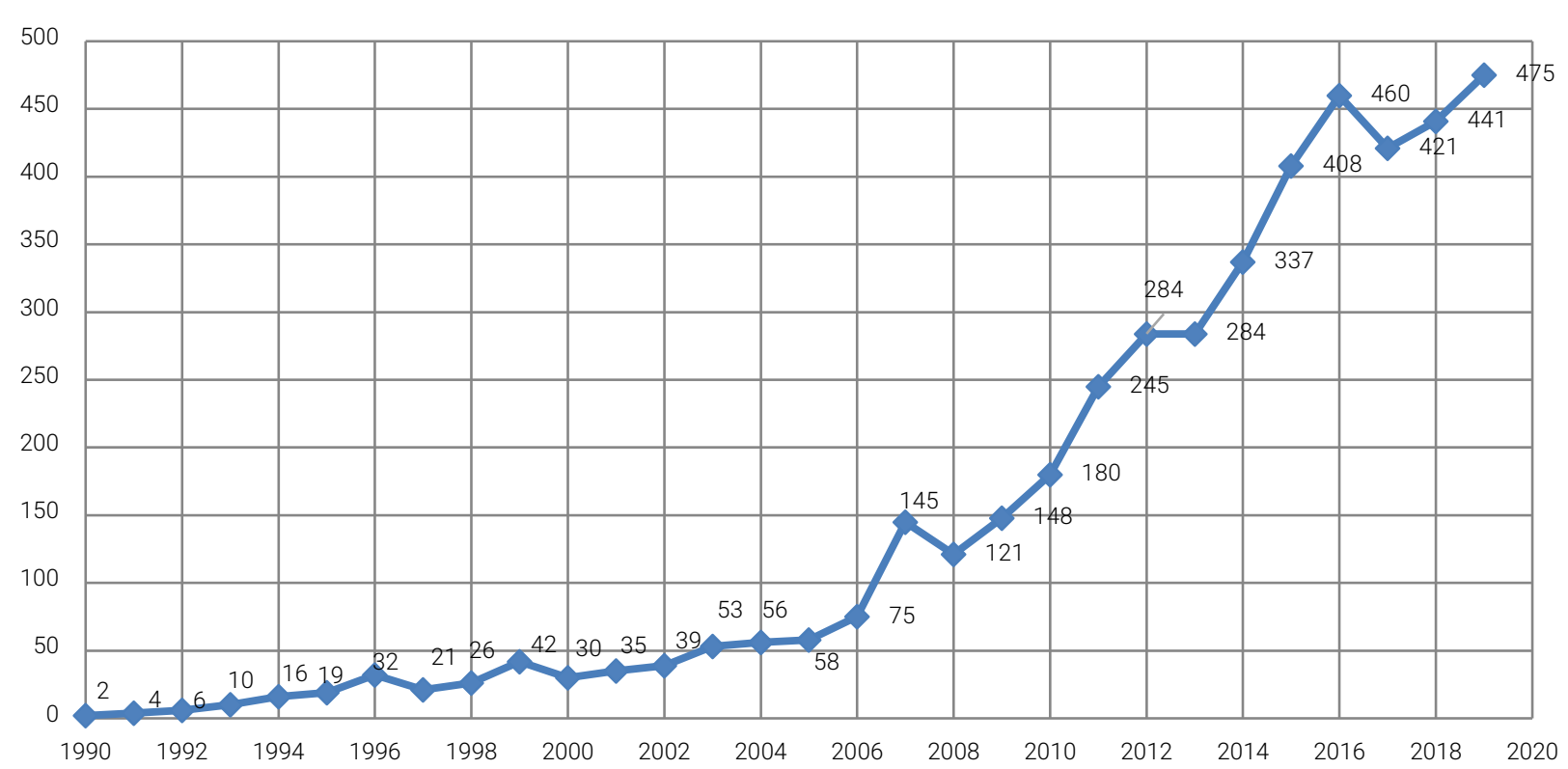

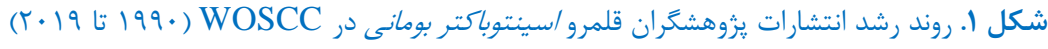

and Chemotherapy

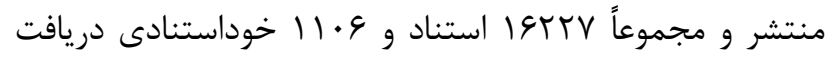
كرده است و در رتبه اول نشريات برتر و يرتوليد قلمرو/سينتوباكتر

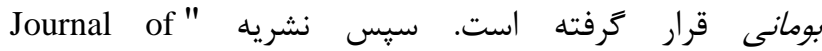
Journal of Clinical "Antimicrobial Chemotherapy Microbiology

\section{اثربخشترين يزوهشگران قلمرو/سينتوباكتر بومانى}

دادههاى جدول ז'، مجموع استنادات، خوداستنادىها، تعداد انتشارات، اج ايندكس، مقالات يراستناد، وابستخى سازمانى و كشور يزوهشگران اثربخش قلمرو/سينتوباكتر بومانى در بازه زمانى . 199 تا 19 • ب نشان مى مهد. اين جدول بر اساس مجموع استنادات دريافتى يزوهشگران اثربخش قلمرو /سينتوباكتر بومانى رتبهبندى شده است.

"Seifert, Harald" Cologne اثربخش قلمرو /سينتوباكتر بومانى قرار گرفته است. سيس Case Western Bonomo, Robert A" Reserve يراستناد قلمرو /سينتوباكتر بومانى قرار ₹رفته است (جدول ؟). زوجهاى هماستنادى برتر در قلمرو/سينتوباكتر بومانى
ضريب رشد انتشارات يزوهشگران قلمرو/سينتوباكتر بومانسى بdمنظور محاسبه ضريب رشد انتشارات علمى ايرانى اسيتوباكتر بومانى از فرمول ضريب رشد (استناد)، استفاده شد.

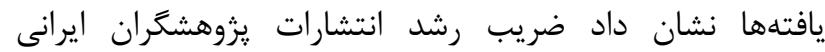
اسينتوباكتر بومانى در WOSCC در بازه زمانى • •199 تا 19 •r

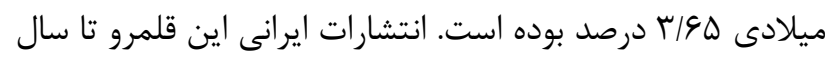

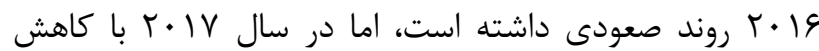

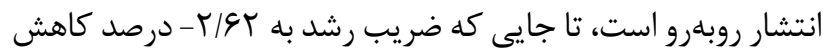
يافته است و مجددا به روال سابق برگشت.

مجلات برتر قلمرو اسينتوباكتر بومانى بر اساس مجموع

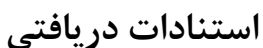
در جدول ا، مجموع استنادات، خوداستنادىها، ضريب تأثير، شاخص جارك Quartile، ناشر، كشور منتشركننده، تعداد مقالات منتشر شده و تعداد مقالات يراستناد مجلات تخصصى قلمرو /سينتوباكتر بومانى استخراج و بر اساس مجموع استنادات دريافتى به رتبهبندى مجلات تخصصى قلمرو /سينتوباكتر بومانى يرداخته شد.

جدول 1 براساس ضريب تاثير مجلات رتبهبندى شده است. بر اين اساس، برترين مجله اين قلمرو براساس ضريب تأثير صباس "Clinical Infectious Diseases" ه/9 داشته و جزء مجلات Q1 است. " Antimicrobial Agents 
جدول 1. مجلات برتر قلمرو/سينتوباكتر بومانى در WOSCC (• 199 تا 19 • ())

\begin{tabular}{|c|c|c|c|c|c|c|c|c|c|}
\hline Rank & Journal & 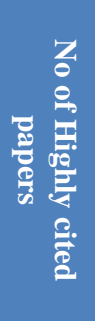 & 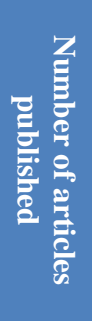 & 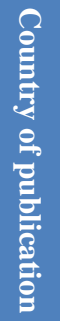 & Publisher & 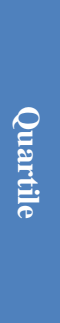 & 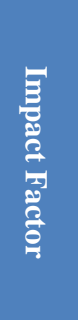 & 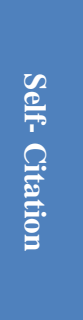 & 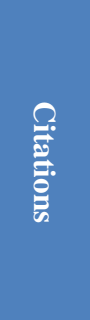 \\
\hline 1 & Clinical Infectious Diseases & 1 & 42 & \multirow{3}{*}{$\stackrel{\Im}{\pi}$} & Oxford University & Q1 & 9.05 & 47 & 4587 \\
\hline 2 & $\begin{array}{l}\text { Clinical Microbiology and } \\
\text { Infection }\end{array}$ & 0 & 79 & & Elsevier & Q1 & 6.42 & 119 & 4162 \\
\hline 3 & $\begin{array}{l}\text { Journal of Antimicrobial } \\
\text { Chemotherapy }\end{array}$ & 6 & 160 & & Oxford University & Q1 & 5.11 & 272 & 8068 \\
\hline 4 & $\begin{array}{l}\text { Journal of Clinical } \\
\text { Microbiology }\end{array}$ & 0 & 111 & \multirow{2}{*}{$\begin{array}{l}\mathcal{I} \\
\infty \\
D\end{array}$} & $\begin{array}{l}\text { American Society for } \\
\text { Microbiology }\end{array}$ & Q1 & 4.95 & 267 & 7173 \\
\hline 5 & $\begin{array}{l}\text { Antimicrobial Agents and } \\
\text { Chemotherapy }\end{array}$ & 6 & 337 & & $\begin{array}{l}\text { American Society for } \\
\text { Microbiology }\end{array}$ & Q1 & 4.71 & 1106 & 16227 \\
\hline
\end{tabular}

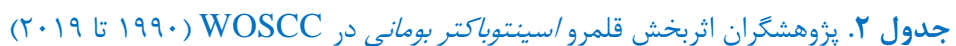

\begin{tabular}{|c|ccccccc|c|}
\hline Rank & Author & Country & Affiliation & $\begin{array}{c}\text { Highly } \\
\text { cited } \\
\text { papers }\end{array}$ & $\begin{array}{c}\text { Self- } \\
\text { Citation }\end{array}$ & $\begin{array}{c}\text { H- } \\
\text { index }\end{array}$ & Record & Citation \\
\hline 1 & Seifert, Harald & Germany & $\begin{array}{c}\text { University } \\
\text { Hospital Cologne }\end{array}$ & 2 & 168 & 24 & 50 & 4365 \\
\hline 2 & $\begin{array}{c}\text { Bonomo, } \\
\text { Robert A }\end{array}$ & USA & $\begin{array}{c}\text { Case Western } \\
\text { Reserve University }\end{array}$ & 2 & 150 & 27 & 71 & 3021 \\
\hline 3 & $\begin{array}{c}\text { Paterson, } \\
\text { David L }\end{array}$ & Australia & $\begin{array}{c}\text { University of } \\
\text { Queensland }\end{array}$ & 1 & 23 & 12 & 15 & 2791 \\
\hline 4 & $\begin{array}{c}\text { Peleg, Anton Y } \\
\text { Nordmann, }\end{array}$ & Australia & Monash University & 0 & 42 & 14 & 20 & 2694 \\
\hline 5 & \begin{tabular}{c} 
Matrice \\
\hline
\end{tabular} & Switzerland & $\begin{array}{c}\text { University of } \\
\text { Fribourg }\end{array}$ & 1 & 93 & 26 & 37 & 2449 \\
\hline
\end{tabular}

جدول r. توزيع فراوانى زوجهاى هماستنادى در مقالات قلمرو /سينتوباكتر بومانى

\begin{tabular}{|c|c|c|c|}
\hline Rank & co-citation couples & No. of Co-Citations & $\begin{array}{c}\text { Countries of co-citation } \\
\text { couples }\end{array}$ \\
\hline 1 & Seifert, Harald * Higgins, Paul G & 54 & Germany* Germany \\
\hline 2 & Nordmann, patrice * Poirel, Laurent & 52 & Switzerland* Switzerland \\
\hline 3 & Hall, Ruth M. * Kenyon, Johanna J & 29 & Australia* Australia \\
\hline 4 & Chen Te-Li * Kuo-Shu CHEN & 28 & Taiwan* Taiwan \\
\hline 5 & Li Jian * Nation, Roger L. & 27 & Australia* Australia \\
\hline 6 & Popova, Anastasiya V. * Schneider, Mikhail M. & 27 & United States* United States \\
\hline 7 & Knirel, Yuriy A. * Shashkov Alexander S. & 27 & Russia Russia* \\
\hline 8 & Chen Te-Li * Lee Yi-tzu & 26 & Taiwan* Taiwan \\
\hline 9 & Popova, Anastasiya V. * Knirel, Yuriy A. & 26 & Russia Russia* \\
\hline 10 & Knirel, Yuriy A. * Schneider, Mikhail M. & 26 & Russia* United States \\
\hline
\end{tabular}


در جدول ع نام يزوهشگَان برتر قلمرو اسينتوباكتر بومانى بر مبناى شاخص مركزيت رتبه نشان داده شده است.

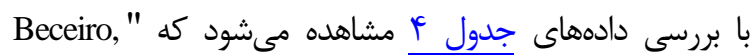
Alejandro

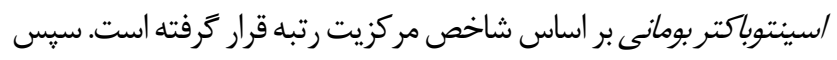
"Zander, Esther" Poza, " جايگاه سوم به شكل مشترك به"

$$
\text { "Margarita }
$$

شِماى كلى از شبكهُ يُزوهشَران يراستناد قلمرو/سيتتوباكتربومانى بر مبناى شاخص مركزيت رتبه نشان داده شده است. در شكل 1

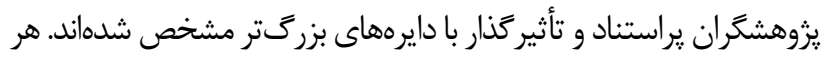

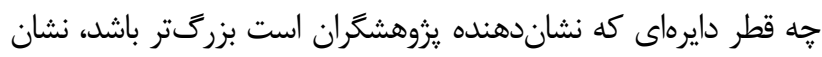
دهنده يِيوندهاى دريافتى زيادتر و تأثير خذارى بيشتر در شبكه است.
بر اساس تجزيه و تحليل دادههاى مربوط به هماستنادى

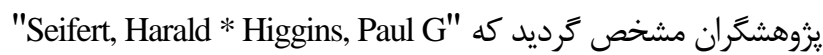

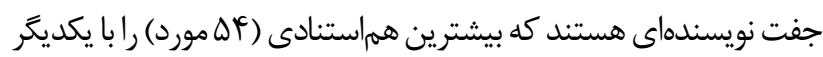
داشتهاند و در رتبه نخست قرار دارند. سيس " *

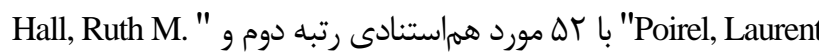
Kenyon, Johanna J

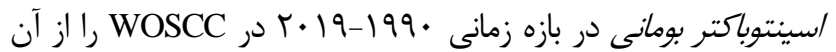
خود كردهاند (جدول سم).

برترين «يخوهشگران قلمرو /سينتوباكتر بومانى براساس شاخص مركزيت رتبه

در ادامه براى تعيين يزوهشًَرانى كه بيشترين اهميت را در زمينهُ

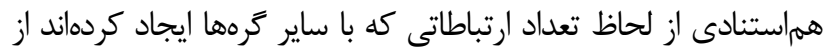
شاخص مركزيت رتبه، بينابينى و نزديكى استفاده شد. گره يا موجوديت

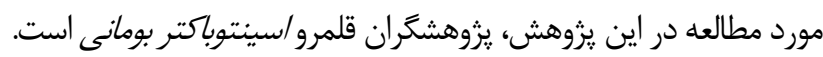

جدول f. برترين يروهشكَران قلمرو /سينتوباكتر بومانى بر مبناى شاخص مركزيت رتبه

\begin{tabular}{|c|c|c|}
\hline Rank & Author & Degree Centrality \\
\hline 1 & Beceiro, Alejandro & 52 \\
\hline 2 & Zander, Esther & 50 \\
\hline 3 & Bonomo, Robert A & 49 \\
\hline 3 & Poza, Margarita & 49 \\
\hline 4 & Roca, Ignasi & 48 \\
\hline 4 & Stefanik, Danuta & 48 \\
\hline 5 & Seifert, Harald & 47 \\
\hline
\end{tabular}

"Kumar Ayush" و "Bahador Abbas" با مركزيت درجه ا جزء ضعيفترين يثوهشكَان قلمرو اسينتوباكتر بومانى بر اساس شاخص مركزيت رتبه هستند و همانطور كه مشاهده مىشود اين يزوهشخران داراى كمترين ييوندهاى دريافتى و ضعيفترين

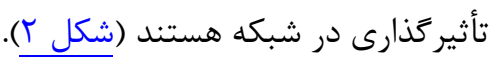

برترين يثوهشگران قلمرو اسينتوباكتر بومانى براساس شاخص مركزيت بينابينى
شكل Y بر اساس دادههاى مركزيت رتبه ترسيم شده است. يزوهشگرانى كه داراى دايرههاى بزرگتر هستند نشاندهنده

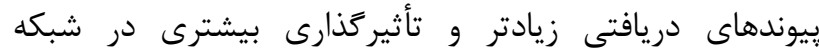

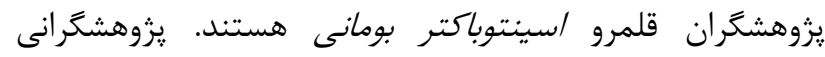

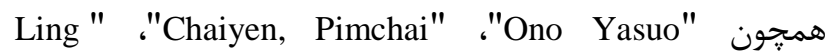
Giamarellou " ،"Godoy-Carter, Veronica" ،"Baodong " . Bai Changqing" "Falagas Matthew E." ."Helen "Nicolau, David P." ."Wang Rui" ‘"David Landman 
"HSU Li Yang" همانگونه كه در جدول ه مشاهده مىشود

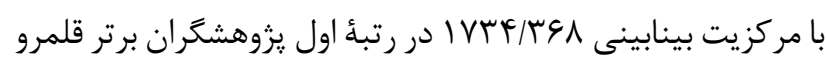
اسينتوباكتر بومانى بر مبناى شاخص مركزيت بينابينى قرار كرفته است. سيس "Adams, Mark D" و و و

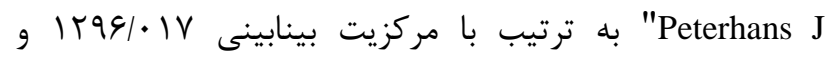

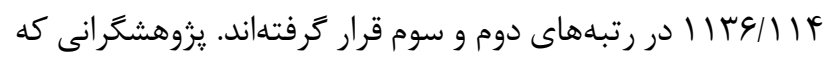
بر حسب جدول ه مركزيت بينابينى بالايى دارند، در واقع به عنوان

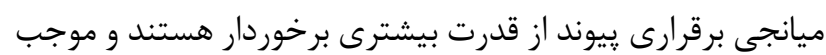

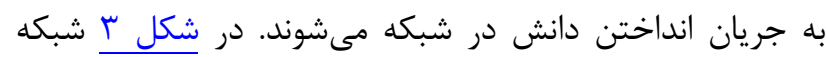
يزوهشگران قلمرو /سينتوباكتر بومانى بر مبناى شاخص مركزيت
در جدول ه نام يروهشگران برتر قلمرو /سينتوباكتر بومانى بر مبناى شاخص مركزيت بينابينى نشان داده شده است. مركزيت

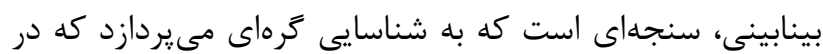

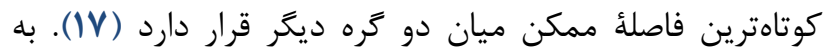
عبارتى ميزان قدرت و تأثير گذارى يك يزوهشگر در شبكه ران ران نشان مىدهد. اين يزوهشگران داراى قدرت ايزوله كردن يا افزايش

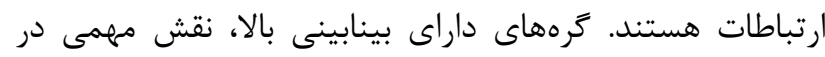
اتصال شبكه ايفا مى كنند و از جايگاهى مركزى در شبكه برخوردار

$$
\text { بينابينى نشان داده شده است. }
$$

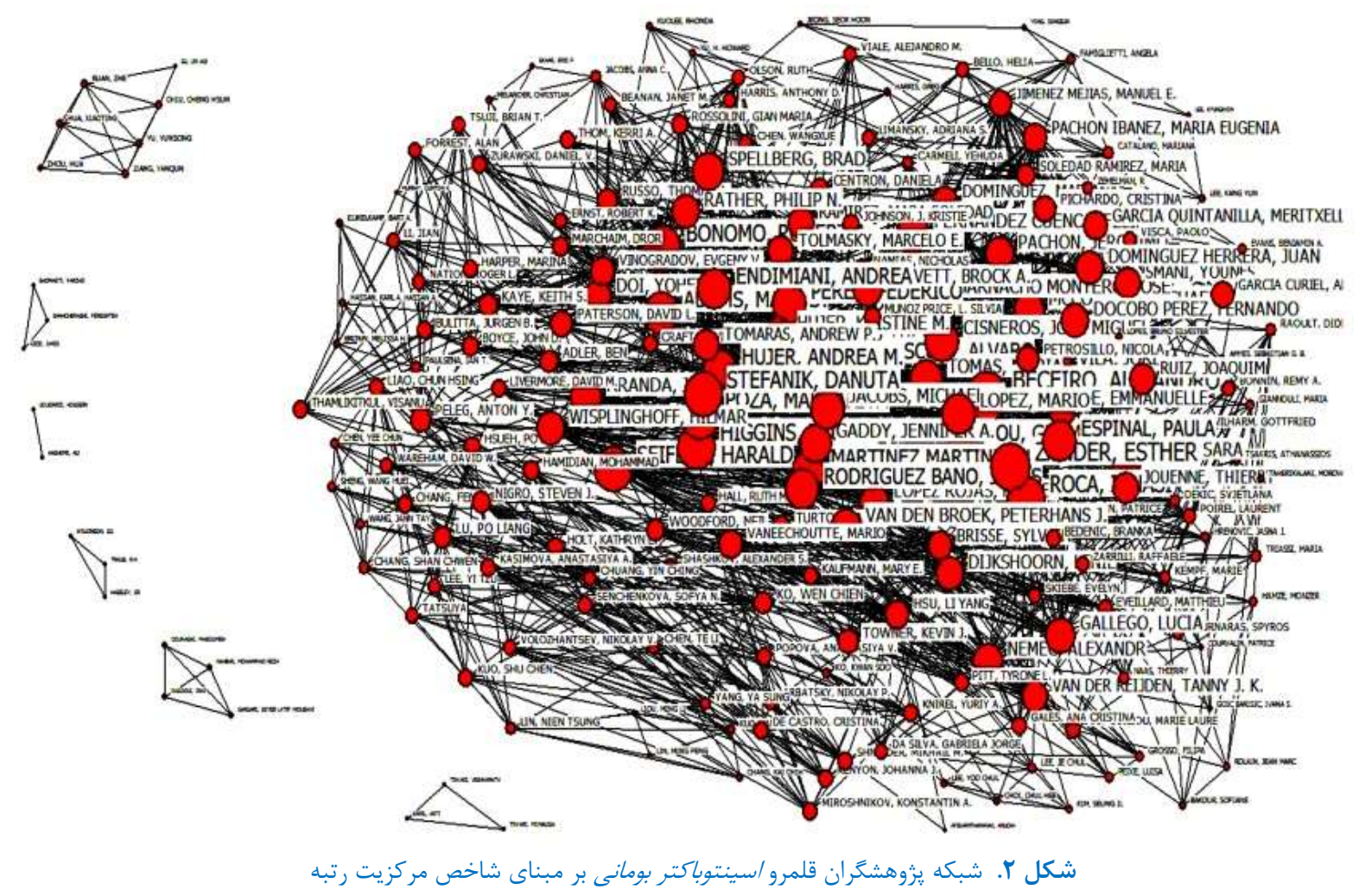

جدول ه. يُوهشًَر برتر قلمرو/سيتتوباكتر بومانى بر مبناى شاخص مركزيت بينابينى

\begin{tabular}{|c|c|c|}
\hline Rank & Author & Betweenness centrality \\
\hline 1 & HSU Li Yang & 1734.368 \\
\hline 2 & Adams, Mark D & 1296.017 \\
\hline 3 & van den Broek, Peterhans J & 1136.114 \\
\hline 4 & Turton, Jane F & 867.635 \\
\hline 5 & Thamlikitkul, Visanu & 710.517 \\
\hline
\end{tabular}




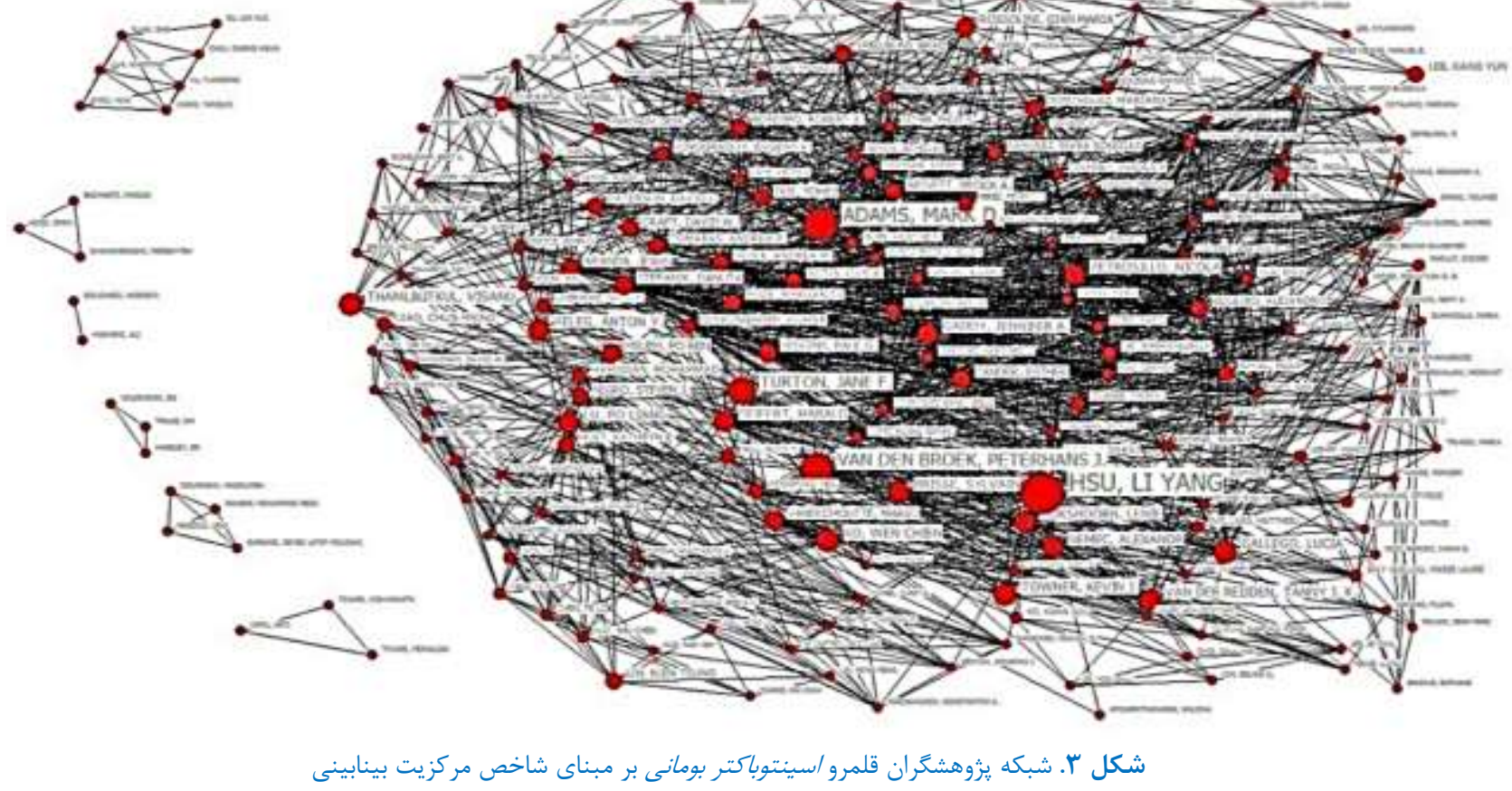

مركزيت نزديكى قرار كرفته است. هijkshoorn, Lenie» و و

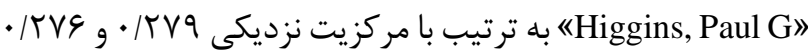
در رتبههاى دوم و سوم قرار گرفتهاند. يزوهشگر انى كه از مركزيت نزديكى بالايى برخودارند شانس بالاترى در همماستنادى با ديگر

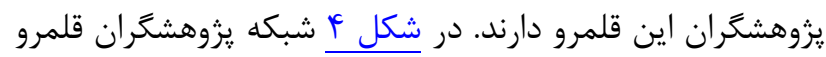
اسينتوباكتر بومانى بر مبناى شاخص مركزيت نزديكى نشان داده شده است.

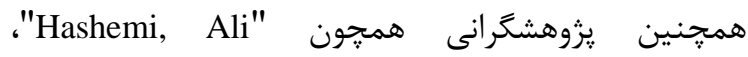
Kumar, " "Bahador, Abbas" "Goudarzi, Hossein" Landman, " “"Wang, Rui" ،"Nicolau, David P" ."Ayush "Falagas, Matthew E" "Bai, Changqing" "David Ono, " ."Godoy Carter, Veronica" ،"Giamarellou, Helen" "Yasuo نزديكى |9 • • • جزء ضعيفترين يزوهشگران قلمرو /سينتوباكتر بومانى بر مبناى شاخص مركزيت نزديكى شناخته شدند.
در اين شكل بزرگترين دايره متعلق به "HSU Li Yang"

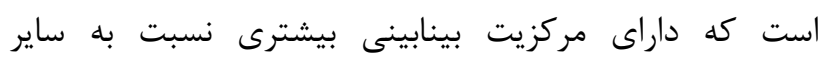
"Adams, Mark D" يروهشخران قلمرو/سينتوباكتر بومانى است و

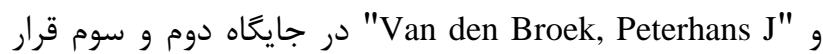
دارند. همجنين يثوهشگرانى همجون "Ling Baodong" "Chaiyen, Pimchai" و "Ono, Yasuo" با مر كزيت بينابينى صفر

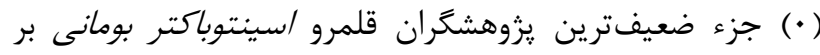
مبناى شاخص مركزيت بينابينى شناخته شدند. اين يزوهشگران قدرت و تأثير حذارى در شبكه ندارند. در جدول צ نام يزوهشگران برتر قلمرو /سيتتوباكتر بومانى بر مبناى شاخص مركزيت نزديكى نشان داده شده است. مركزيت

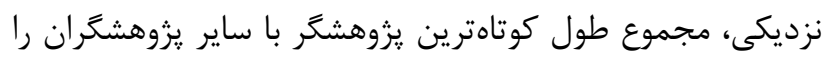
مشخص مى كند. به عبارت ديخر مى توان كَفت يزوهشخرانى كه از مركزيت نزديكى بالايى برخودارند شانس بالاترى در هماستنادى با

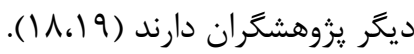

Seifert, " همانگونه كه در جدول 9 مشاهده مىشود

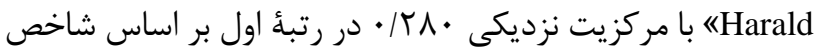


جدول 9. يُوهشكَران برتر قلمرو/سينتوباكتر بومانى بر مبناى شاخص مركزيت نزديكى

\begin{tabular}{|c|c|c|}
\hline Rank & Author & Closeness Centrality \\
\hline 1 & Seifert, Harald & $0 / 280$ \\
\hline 2 & Dijkshoorn, Lenie & $0 / 279$ \\
\hline 3 & .Higgins, Paul G & $0 / 276$ \\
\hline 4 & Bou, German & $0 / 273$ \\
\hline 5 & Bonomo, Robert A. & $0 / 272$ \\
\hline
\end{tabular}

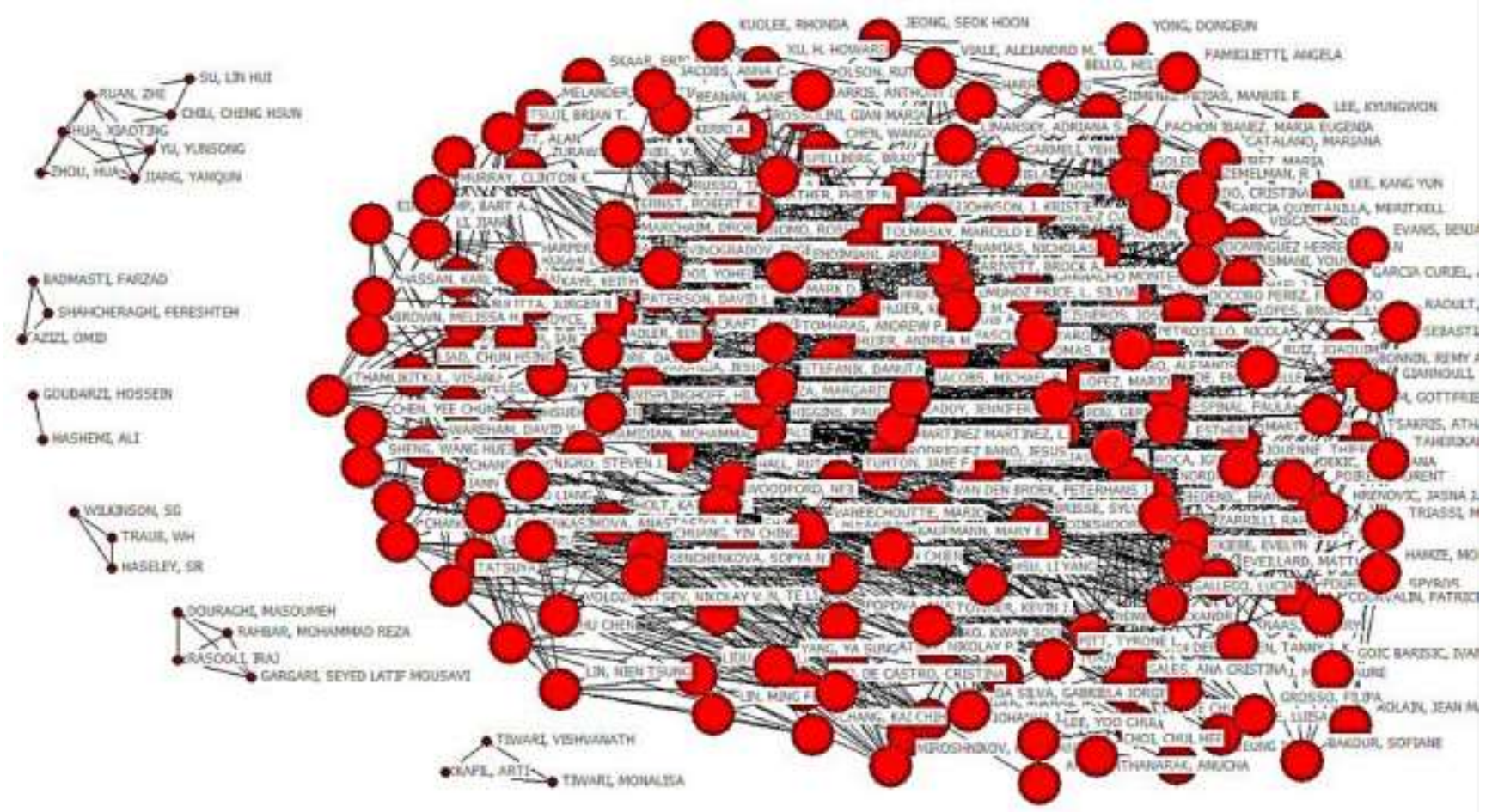

شكل f. شبكه يُوهشكَران قلمرو/سينتوباكتر بومانى بر مبناى شاخص مركزيت نزديكى

بحث

كيفيت مجلات، يكى از مواردى است كه همواره مورد توجه

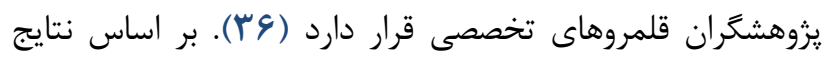
يزوهش، مجله "Clinical Infectious Diseases" برترين مجلئ قلمرو /سينتوباكتر بومانى شناسايى كرديد كه با دارا بودن بالاترين

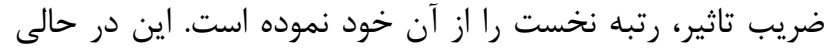

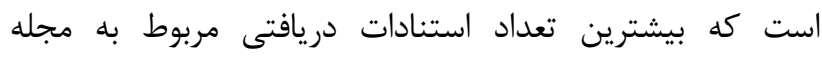

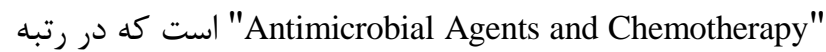

$$
\text { ينجم قرار دارد (جدول (). }
$$

از آنجاكه در يزوهشهاى علمسنجى، شمارش تعداد

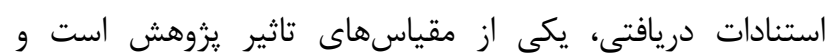
"يراستنادها《 مترادف با 》اثربخشها《) در نظر كرفته مىشوند،
يزروهش حاضر، شبكة همكارى علمى يزوهشكَران قلمرو

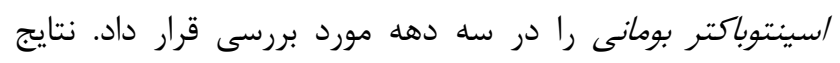

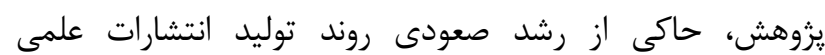

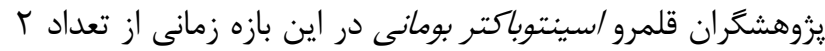

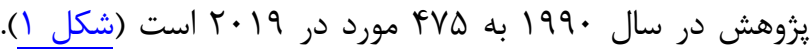

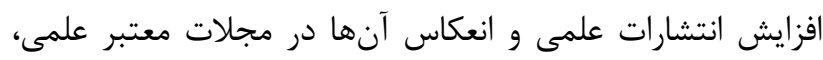
نشاندهندة وجود دغدغه متخصصين امر در سطح جهان در قلمرو آنارئ مورد يزوهش است كه بازتاب آن در قالب مقالات علمى بهات

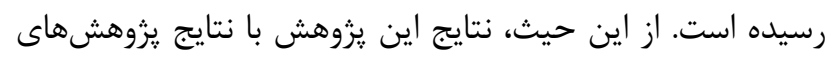

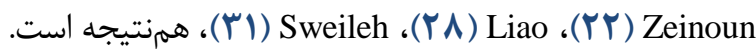


مركزيت بينابينى، از مهمترين سنجهها مركزيت بهشمار مىروند (IV)

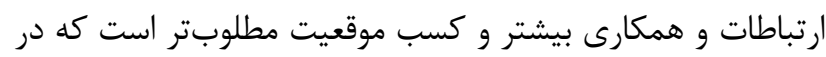
نهايت موجب قدرتمندتر شدن آن فرد در شبكه اجتماعى است. بنابراين، اثربخشى يزوهشكران، تنها متاثر از انتشارات آنان نيست فردان

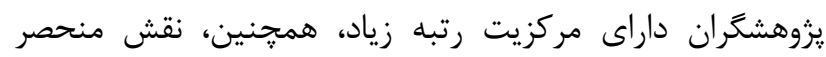
بلفردى در جذب افراد جديد به شبكه علمى دارئ دارند، بنابراين

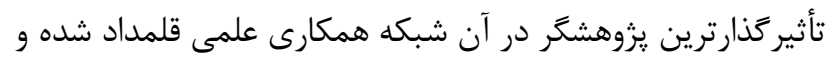

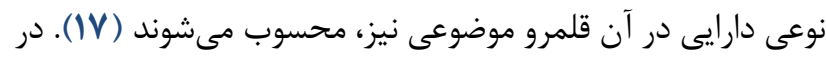

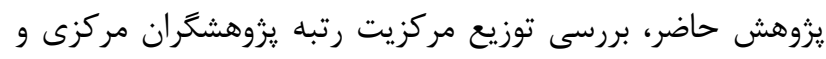

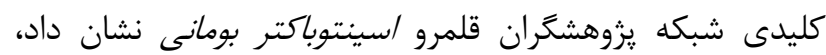
حانئiro, Alejandro"

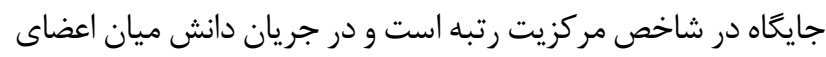

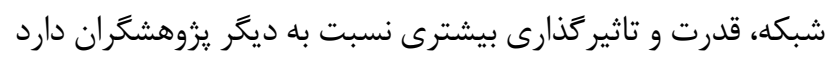

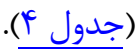

از آنجا كه، در شبكأ همكارى علمى، بلمنظور اعمال تاثير و

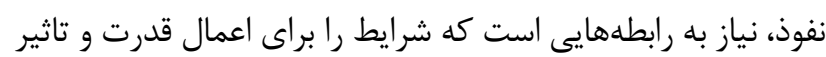
فراهم آورد لذا وجود يزوهشكرى كه بين گَروههايى از افراد، ارتباط

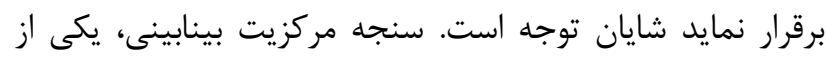

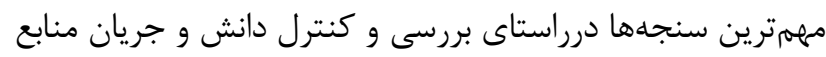

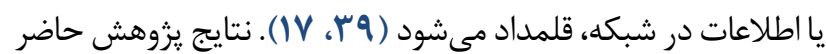
بيانكر آن است كه "HSU Li Yang" با مركزيت بينابينى

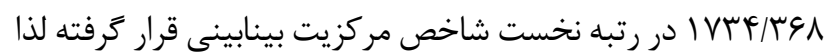

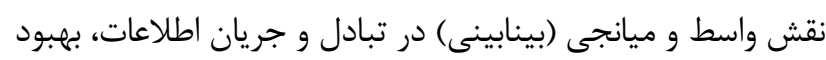

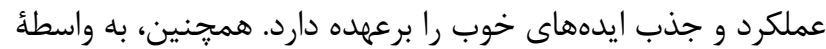

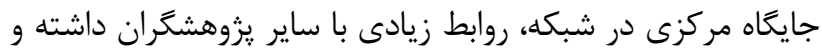

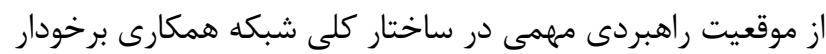

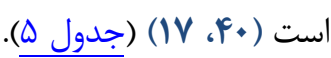

يافتهاى يزوهش در بررسى سنجأ مركزيت نزديكى، حاكى

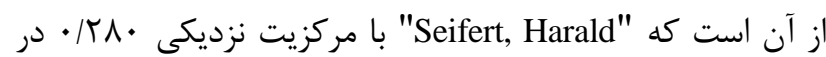

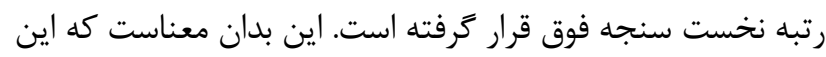
نويسنده به اعضاى ديگر در شبكه نزديكتر بوده و سريعتر از هر فرد

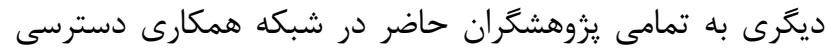

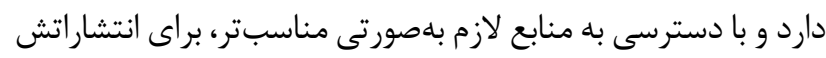

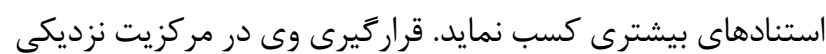

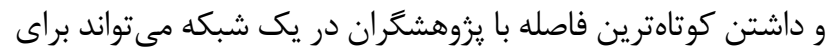

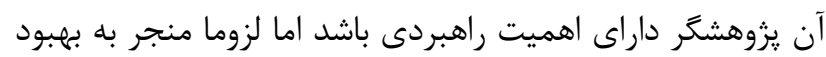

بنابراين نويسندكان براستناد، نويسندكان اثربخشى در جامعه علمى

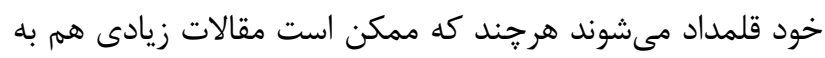

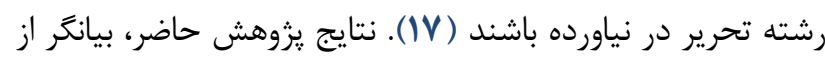
آن است كه "Seifert, Harald" با دريافت ه\&بع استناد از كشور آلمان و دانشخاه- بيمارستان Cologne با بالاترين، استناد دريافتى،

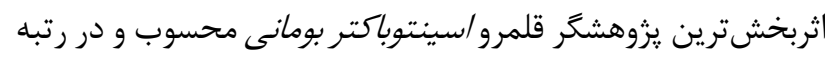
نخست يزوهشكران قرار دارد. نتايج همجنين تَواه آن است، Bonomo, Robert A"

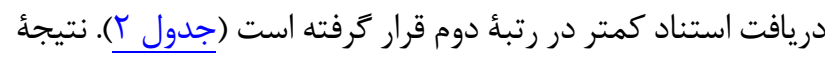

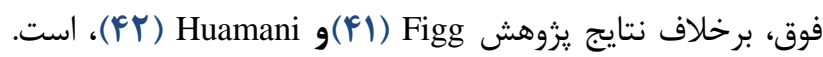

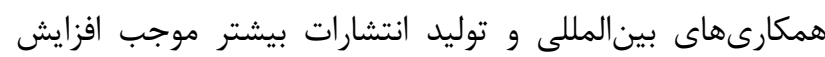
استنادات دريافتى يزوهشكَران نشده است كه در اين بين بحث

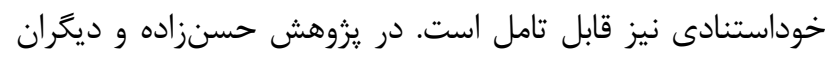

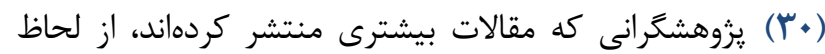

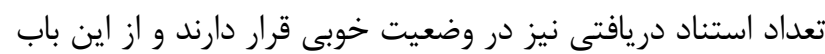

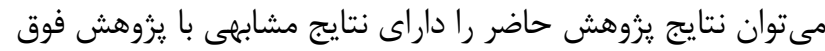

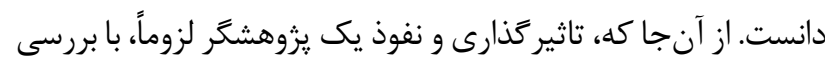
تعداد انتشارات و توليدات علمى آن يزوهشكر قابل سنجش نئ نيست،

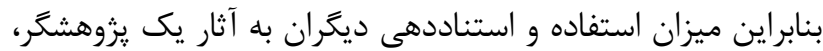

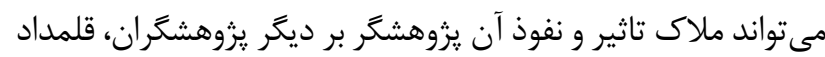

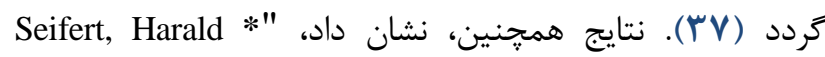
Higgins, Paul G اسينتوباكتر بومانى محسوب مىشوند. زوجهاى هماستنادى در يك

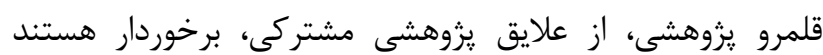

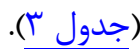
در يك شبكؤ همكارى علمى، همواره افراد، در ارتباط با ساير

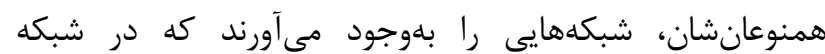

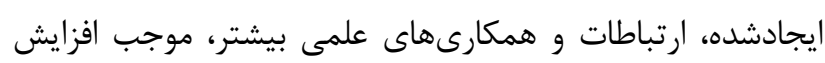
عملكرد يزوهشكران و دريافت استنادات بيشتر آنان مىشود (IV). تحليل شبكههاى اجتماعى و بررسى انواع و تعداد بيوندها و روابطى

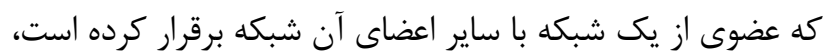

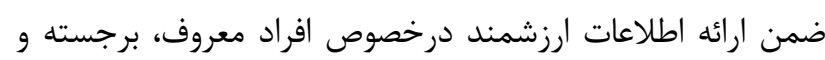

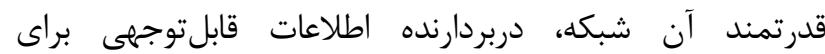
برنامهريزى، مديريت و ويشبينى اهداف بلندمدت و كوتاهدت

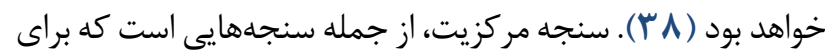

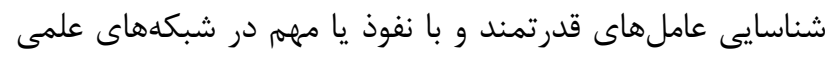
مورد استفاده قرار مى گيرد. مركزيت رتبه، مركزيت نزديكى و 


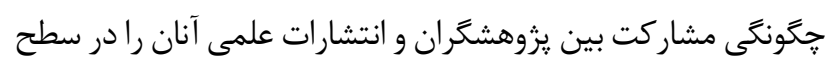

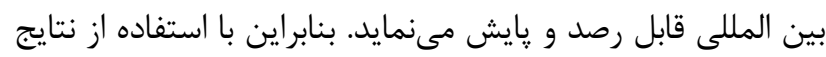

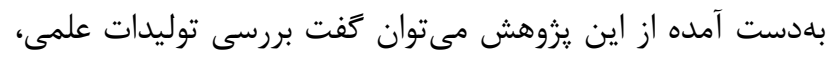

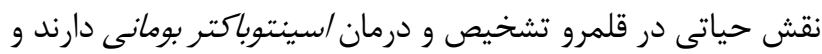

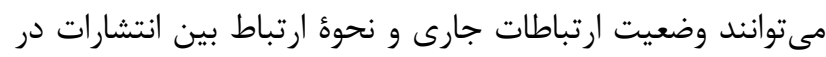
اين قلمرو را نمايش داده و ارتباط با محققين اين حوزه ران رات تسهيل كند.

براين اساس بيشنهاد مىشود، مطالعه دقيقى بر روى شبكه

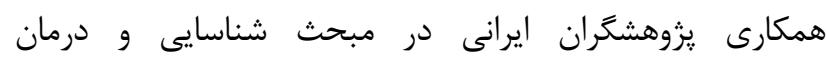

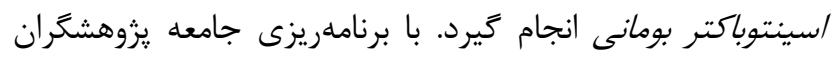

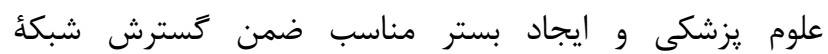

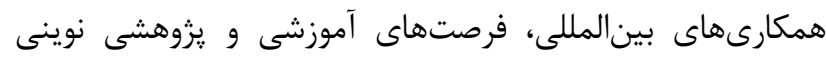

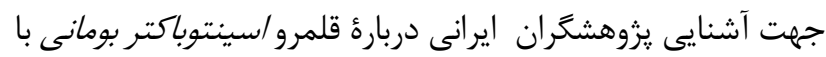

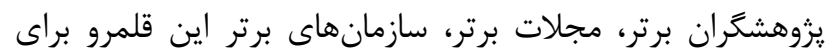
همكارى هاى موثرتر جهانى ايجاد خواهد شد.

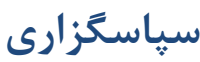

بدينوسيله، از تمامى تمامى متخصصينى كه در انجام اين يزوزهش ما را يارى كردند، سياسگزارى مى كنيم.

\section{تعارض در منافع}

اين مقاله يزوهشى مستقل است كه بدون حمايت مالى إنى

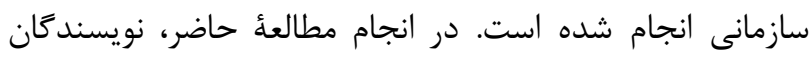
هيج كونه تضاد منافعى نداشتهاند.

\section{Referance}

1. Saleh, NM, Hesham MS, Amin MA, Samir Mohamed R. Acquisition of Colistin Resistance Links Cell Membrane Thickness Alteration with a Point Mutation in the lpxD Gene in Acinetobacter Baumannii. Antibiotics, 2020; 9, 164. [DOI:10.3390/antibiotics9040164] [PMID] [PMCID]

2. Nurtop E, Baylndlr Bilman F, Menekse S, Kurt Azap O, Gonen M, Ergonul O, Can F. Promoters of Colistin Resistance in Acinetobacter Baumannii Infections. Microbial Drug Resistance, 2019; 25(7): 997-1002. [DOI:10.1089/mdr.2018.0396] [PMID]

3. Lee C-R, Lee JH, Park M, Park KS, Bae IK, Kim YB, Cha C-J, Jeong BC and Lee SH Biology of Acinetobacter
عملكرد وى نيست. زيرا فرصت و شانس بالاتر در برقرارى ارتباط با

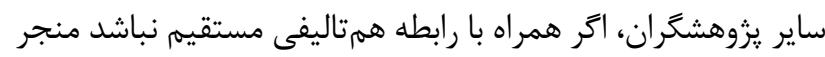

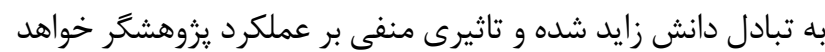

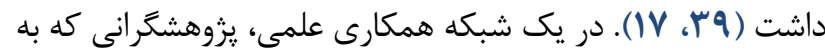

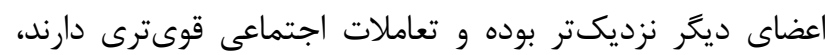

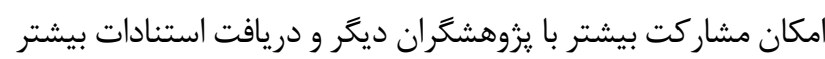

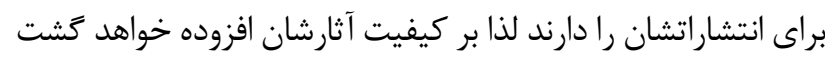

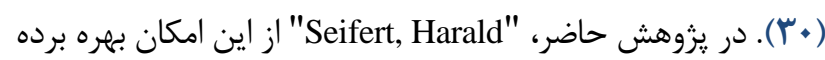

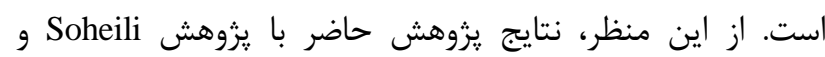

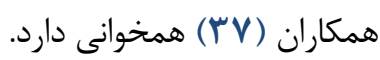

$$
\text { نتيجه گيرى }
$$

يكى از مهمترين مفاهيم و كاربردهاى منحصر بهفرد تحليل

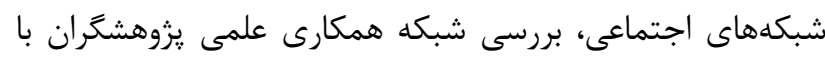

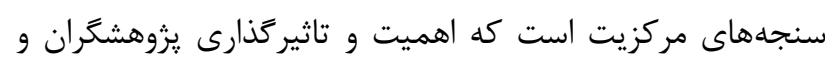

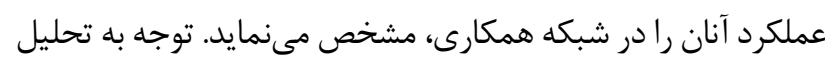

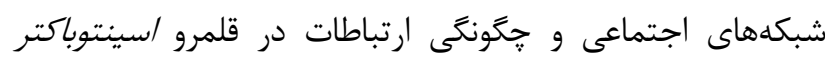

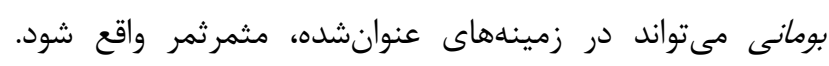

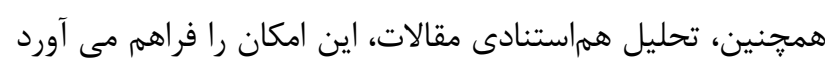

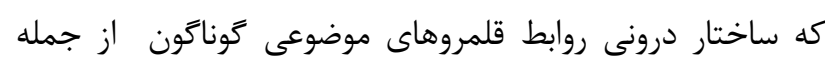

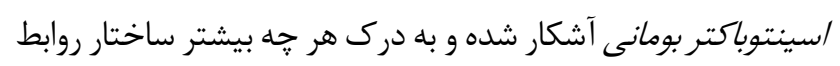

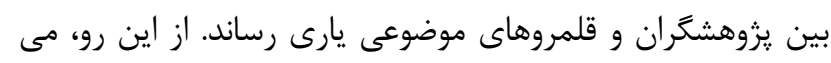

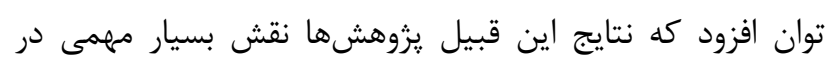

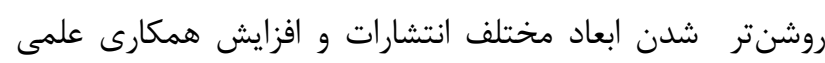

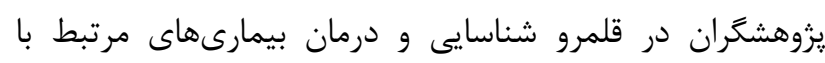

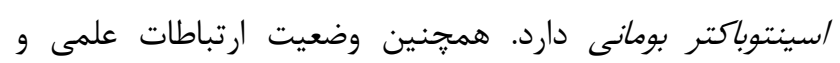

Baumannii: Pathogenesis, Antibiotic Resistance Mechanisms, and Prospective Treatment Options. Front. Cell. Infect. Microbiol, 2017; 7:55. [DOI:10.3389/fcimb.2017.00055]

4. Pormohammad A, Mehdinejadiani K, Gholizadeh P, et al. Global prevalence of colistin resistance in clinical isolates of Acinetobacter Baumannii: A systematic review and meta-analysis. Microbial Pathogenesis, 2020; 139:103887. [DOI:10.1016/j.micpath.2019.103887] [PMID]

5. Wang X, Qin LJ. A review on Acinetobacter Baumannii. J Acute Dis, 2019; 8: 16-20. [DOI:10.4103/2221$\underline{6189.250373]}$ 
6. Lin MF, Lan CY. Antimicrobial resistance in Acinetobacter Baumannii: from bench to bedside. World J. Clin. Cases, 2014; 2, 787-814. [DOI:10.12998/wjcc.v2.i12.787] [PMID] [PMCID]

7. Wong D, Nielsen TB, Bonomo RA, Pantapalangkoor P, Luna BM, Spellberg BJ. Clinical and Pathophysiological Overview of Acinetobacter Infections: a Century of Challenges. Clinical microbiology reviews, 2016; 301 , 409-447. [DOI:10.1128/CMR.00058-16] [PMID] [PMCID]

8. Levi I, Rubinstein E. Acinetobacter infections-overview of clinical features. In: Bergogne-Berezin E, Joly-Guillou M L, Towner K J, editors. Acinetobacter: microbiology, epidemiology, infections, management, 1996. New York, N.Y: CRC Press; 1996. pp. 101-115.

9. Karyne R, Curty Lechuga G, Almeida Souza AL, Rangel da Silva Carvalho JP, Simões Villas Bôas MH, De Simone SG. Pan-Drug Resistant Acinetobacter Baumannii, but Not Other Strains, Are Resistant to the Bee Venom Peptide Mellitin. Antibiotics, 2020; 9, 178. [DOI:10.3390/antibiotics9040178] [PMID] [PMCID]

10. Da Silva GJ, Domingues S. Interplay between Colistin Resistance, Virulence and Fitness in Acinetobacter Baumannii. Antibiotics, 2017; 6, 28. [DOI:10.3390/antibiotics6040028] [PMID] [PMCID]

11. World Health Organization (WHO). WHO Publishes List of Bacteria for Which New Antibiotics Are Urgently Needed; WHO: Geneva, Switzerland, 2017.

12. Hoang Quoc C, Nguyen Thi Phuong, T, Nguyen Duc H, Tran Le T, Tran Thi Thu H, Nguyen Tuan S, Phan Trong L. Carbapenemase Genes and Multidrug Resistance of Acinetobacter Baumannii: A Cross Sectional Study of Patients with Pneumonia in Southern Vietnam. Antibiotics, 2019; $\quad 8, \quad 148$ [DOI:10.3390/antibiotics8030148] [PMID] [PMCID]

13. Aybar Türkoğlu M, Topeli Iskit A. Ventilator associated pneumonia caused by high risk microorganisms: a matched case-control study. Tuberk Toraks, 2008; 56(2): $139-49$

14. Maccain KW, Whitney PJ. Contrasting assessments of interdisciplinarity in emerging specialties. Knowledge: Creation, Diffusion, Utilization, 1994; 15(3): 285-306. [DOI:10.1177/107554709401500303]

15. Chen C, Chen Y, Horowitz M, Hou H, Liu Z, Pellegrino D. Towards an Explanatory and Computational Theory of Scientific Discovery 1 Introduction. Journal of Informetrics Special Issue on Science of Science, 2009; 132.

16. Shiffrin RM, Borner K. Introduction. In: Mapping knowledge domains. PNAS, 2004, 101, Suppl, 1: 51835185. [DOI:10.1073/pnas.0307852100] [PMID] [PMCID]

17. Tajedini O, Soheili F, Sadatmoosavi A. The Centrality Measures in Co-authorship Networks: Synergy or
Antagonism in Researchers' Research Performance. Iranian Journal of Information Processing \& Management, 2019; 34 (3):1423-1452. (In Persian)

18. Soheili F, Osareh F. Concepts of Centrality and Density in Scientific and Social Networks. National Studies on Librarianship and Information Organization, 2013; 24(3): 92-108. (In Persian)

19. Leydesdorff L, Wagner CS, Bornmann L. Betweenness and diversity in journal citation networks as measures of interdisciplinarity-A tribute to Eugene Garfield. Scientometrics, 2018; 114(2): 567-592. [DOI:10.1007/s11192-017-2528-2] [PMID] [PMCID]

20. Goltaji M, Behzadi Z. Citation Analysis and Histographic Outline of Scientific Output in Pathology by the Middle East countries Using Science Citation Index during 20002009. National Studies on Librarianship and Information Organization, 2014; 25(2): 68-84. (In Persian)

21. Zou Lu-Xi, Sun L. Visualization analysis of health informatics research from 2001 to 2018. Current Science, 2020; 118, 5: 714-721.

22. Zeinoun P, Akl EA, Maalouf FT and Meho LI. The Arab Region's Contribution to Global Mental Health Research (2009-2018): A Bibliometric Analysis. Front. Psychiatry, 2020; 11:182. [DOI:10.3389/fpsyt.2020.00182] [PMID] [PMCID]

23. Liu F, Wu TT, Lei G and et al. Worldwide tendency and perspectives in traumatic dental injuries: A bibliometric analysis over two decades (1999-2018). Dent Traumatol, 2020; 00: 1- 9. [DOI:10.1111/edt.12555] [PMID]

24. Kınıkoğlu O, Güven YÖ, Kılboz BB. Publication and Citation Analysis of Medical Doctors' Residency Master's Theses Involving Animal Experiments on Rats in Turkey. Alternatives to Laboratory Animals, 2020; 026119292090722. [DOI:10.1177/0261192920907226] [PMID]

25. He S, Zhao Y, Fan Y, Zhao X, Yu J, Xie J, Wang C, Su J. Research Trends and Hotspots Analysis Related to Monocarboxylate Transporter 1: A Study Based on Bibliometric Analysis. Int. J. Environ. Res. Public Health, 2019; 16, 1091. [DOI:10.3390/ijerph16071091] [PMID] [PMCID]

26. Seo B, Kim J, Kim S, Lee E. Bibliometric analysis of studies about acute myeloid leukemia conducted globally from 1999 to 2018. Blood Res, 2020; 55(1): 1-9. [DOI:10.5045/br.2020.55.1.1] [PMID] [PMCID]

27. Zhou H, Tan W, Qiu Z, Song Y, Gao S. A bibliometric analysis in gene research of myocardial infarction from 2001 to 2015. PeerJ, 2018; 6: e4354. [DOI:10.7717/peerj.4354] [PMID] [PMCID]

28. Liao H, Tang M, Luo LM, Li C, Chiclana F, Zeng X. A Bibliometric Analysis and Visualization of Medical Big Data Research. Sustainability, 2018; 10,166: 1-18. [DOI:10.3390/su10010166] 
29. Xing D, Zhao Y, Dong S, Lin J. Global research trends in stem cells for osteoarthritis: a bibliometric and visualized study. Int J Rheum Dis, 2018; 21: 1372-1384. [DOI:10.1111/1756-185X.13327] [PMID]

30. Hasanzadeh, P., Isfandyari-Moghaddam, A., soheili, F. (2018). 'Co-authorship and the Re-lationship between Social Influ-ence and the Extent of Effec-tiveness and Productivi-ty of Re-searchers in Domain of Chronic Cardiovas-cular Fail-ure'. Journal of Scientometrics, 2018; 4(8): 143-160.(In Persian)

31. Sweileh WM, Shraim NY, Al-Jabi SW, Sawalha AF, AbuTaha AS, Zyoud SH. Bibliometric analysis of global scientific research on carbapenem resistance (1986-2015). Annals of Clinical Microbiology and Antimicrobials, 2016; 15(1). [DOI:10.1186/s12941-016-0169-6] [PMID] [PMCID]

32. Analytics, C. Web of Science platform: Web of Science: Summary of Coverage, 2020; Available online: https: //clarivate.libguides.com/webofscienceplatform/coverage (accessed on 18 March 2020).

33. Birkle C, Pendlebury DA, Schnell J, Adams J. Web of Science as a data source for research on scientific and scholarly activity. Quantitative Science Studies, 2020; 1(1): 363-376. [DOI:10.1162/qss_a 00018]

34. Khaleghi N. A Glance at Evaluative Indexes in Science and Technology. National Studies on Librarianship and Information Organization, 2007; 18(3), 91-106. (In Persian)

35. Jin B, Liang L, Rousseau R, Egghe L. The R-and ARindices: Complementing the h-index. Chinese science bulletin. 2007; 52: 855-63. [DOI:10.1007/s11434-0070145-9]

36. Danesh F, Ghavidel S. Coronavirus: Scientometrics of 50 Years of Global Scientific Productions. Iran J Med Microbiol, 2020; 14 (1):1-16. (In Persian) [DOI:10.30699/ijmm.14.1.1]

37. Soheili F, Sharif Moghaddam H, Mousavi Chelak A, Khasseh A A. An Evaluation of iMetric Studies through the Scholarly Influence Model. Iranian Journal of Information Processing \& Management, 2016; 32 (1) :2550.(In Persian)

38. Soheili F, Osareh F. 'Concepts of Centrality and Density in Scientific and Social Networks'. National Studies on Librarianship and Information Organization, 2013; 24(3): 92-108. (In Persian)

39. Soheili F, Mansoori A. The Analysis of the Iranian Chemistry co-Authorship Network using Centrality Measure. Journal of Library and Information Science Studies, 2014; 21(Vol.6, No.13): 89-106. (In Persian)

40. Burt RS. Structural Holes: The Social Structure of Competition. Massachusetts: Harvard University Press, 1992.
41. Figg WD, Dunn L, Liewehr DJ, Steinberg SM, Thurman PW, Barrett JC, Birkinshaw J. Scientific Collaboration Results in Higher Citation Rates of Published Articles. Pharmacotherapy: The Journal of Human Pharmacology and Drug Therapy, 2006; 26: 759-767. [DOI:10.1592/phco.26.6.759] [PMID]

42. Huamani C, Rey de Castro J, Gonzalez-Alcaide G, Polesel DN, Tufik S, Andersen ML. Scientific research in obstructive sleep apnea syndrome: bibliometric analysis in SCOPUS, 1991-2012. Sleep Breath, 2015; 19(1):109-14. [DOI:10.1007/s11325-014-0969-x] [PMID] 